\title{
Samambaias e licófitas de um fragmento de Mata Atlântica na Serra da Jiboia, Bahia, Brasil
}

\author{
Taís Soares Macedo ${ }^{1}$, Aristóteles Góes-Neto ${ }^{1} \&$ Fabiana Regina Nonato ${ }^{2}$
}

${ }^{1}$ Programa de Pós-graduação em Botânica, Departamento de Ciências Biológicas, Universidade Estadual de Feira de Santana, Av. Transnordestina, s/n, 44036-900, Feira de Santana, Bahia, Brasil.

${ }^{2}$ Centro de Pesquisas Gonçalo Moniz, Fundação Oswaldo Cruz, Rua Waldemar Falcão, 121, 40296-710, Salvador, Bahia, Brasil.

\begin{abstract}
Resumo - É apresentado um levantamento das samambaias e licófitas de um encrave de Mata Atlântica na região semiárida. A Serra da Jiboia corresponde a um pequeno conjunto de morros que abriga vários tipos vegetacionais: caatinga na base, mata higrófila na encosta e campo rupestre no topo, sendo considerada uma área prioritária para conservação da biodiversidade da Mata Atlântica brasileira. Foram realizadas coletas mensais entre os anos de 2009 e 2010. O material coletado encontra-se depositado no herbário HUEFS. Foram encontradas 97 espécies, em 51 gêneros e 22 famílias; Elaphoglossum iguapense, E. itatiayense e Pecluma sicca são novos registros para o Nordeste. São apresentadas chaves de identificação para as famílias e para as espécies, bem como comentários e distribuição geográfica.
\end{abstract}

Palavras-chave adicionais: Flora, Florestas Pluviais, Lycophyta, Monilophyta, Nordeste do Brasil.

\begin{abstract}
Ferns and lycophytes from a fragment of Atlantic forest in the Serra da Jiboia, Bahia, Brazil) - A floristic survey of ferns and lycophytes from an area of Atlantic Rain Forest in the semi-arid region is presented. The Serra da Jiboia is a small set of hills which hosts several vegetation types: caatinga at the base, wet forests on the slope and campos rupestres (rocky fields) on the top; this is one of the prioritary areas for biodiversity conservation of the Brazilian Atlantic Forest. Field trips to collect material were carried out monthly, between 2009 and 2010. The specimens are deposited in HUEFS. A total of 97 species, in 51 genera and 22 families, were found; Elaphoglossum iguapense, E. itatiayense e Pecluma sicca are recorded for the first time from Northeast Brazil. Identification keys to families and species, as well as comments and geographic distribution are presented.

Additional key words: Flora, Lycophyta, Monilophyta, Northeast Brazil, rain forests.
\end{abstract}

Na Bahia, ainda existe uma lacuna no conhecimento das samambaias e licófitas. Tais grupos têm sido citados em trabalhos mais amplos, envolvendo a flora vascular como um todo. Entre os levantamentos específicos para esses grupos, destacam-se os realizados na Chapada Diamantina por Edwards (1995), Øllgaard (1995), Prado (1995), Barros (1998), Barros \& Araújo (2000), Prado (2003), Nonato (2005) e Ferreira (2009). Apesar das samambaias e licófitas estarem distribuídas principalmente em áreas de Floresta Atlântica do Brasil, como discutido em Labiak \& Prado (1998) e Salino \& Almeida (2009), trabalhos realizados na Bahia ainda são escassos neste bioma (Noblick \& Brito 1984; Paciência \& Prado 2004, 2005; Matos et al. 2010).

A região da Serra da Jiboia é um enclave de Mata Atlântica inserido na região semiárida, sendo uma áreas de extrema importância biológica na Bahia e prioritária para conservação da biodiversidade deste bioma no Brasil (Conservação Internacional do Brasil et al. 2000). Trabalhos realizados na Serra da Jiboia, como os de Carvalho-Sobrinho \& Queiroz (2005) com fanerógamas, Valente \& Porto (2006) com hepáticas, Marques et al. (2007) com fungos conidiais e Góes-Neto et al. (2003) com fungos Aphyllophorales, apontam uma grande diversidade de espécies, algumas delas endêmicas. Com esta perspectiva, o presente estudo reali-

*Autora para correspondência: taismacedo10@yahoo.com.br Editor responsável: Luciano Paganucci de Queiroz

Submetido em: 5 set. 2011; publicação eletrônica: 19 dez. 2012 zou o levantamento das samambaias e licófitas da Serra da Jiboia, ampliando as informações sobre a Mata Atlântica do Nordeste do Brasil.

\section{Material e Métodos}

A Serra da Jiboia está localizada no município de Santa Teresinha (estado da Bahia), próximo aos limites dos municípios de Castro Alves e Elísio Medrado, na microrregião geográfica de Feira de Santana. O fragmento estudado encontra-se mais precisamente no Morro da Pioneira, extremo norte da Serra, entre as coordenadas $12^{\circ} 51^{\prime} \mathrm{S}$ e $39^{\circ} 48^{\prime} \mathrm{W}$. A região é formada por um pequeno conjunto de morros e abriga vários tipos vegetacionais: caatinga na base, floresta ombrófila na encosta, entre 400 e 800 m s.n.m., e campo rupestre sobre afloramentos rochosos de origem gnáissicogranítica no topo (Queiroz et al. 1996). O clima da região é tropical semiúmido com temperatura média anual de $22^{\circ} \mathrm{C}$, variando em função da altitude. O índice pluviométrico é de aproximadamente $1200 \mathrm{~mm}$ ano $^{-1}$ (Sandes 2003).

Foram realizadas excursões de coletas mensais à área de estudo, durante os anos de 2009 e 2010 . O material botânico foi coletado e herborizado de acordo com as técnicas descritas por Windisch (1992) e identificado a partir de bibliografia específica, seguindo a classificação de Smith et

Sitientibus série Ciências Biológicas 12(2): 269-291. 2012. 
al. $(2006,2008)$ para as samambaias e Kramer \& Green (1990) para as licófitas.

Os dados de distribuição geográfica estão baseados em bibliografia específica e dados de herbários. Todo material coletado encontra-se depositado no Herbário da Universidade Estadual de Feira de Santana (HUEFS). Também foram incluídos materiais das coleções dos herbários ALCB, HRB e HUEFS (siglas segundo Thiers 2010). A abreviação dos nomes dos autores segue Pichi-Sermolli (1996). Os termos utilizados para os caracteres seguem Lellinger (2002).

\section{Resultados}

Foram registradas 92 espécies de samambaias, distribuídas em 48 gêneros e 20 famílias, representando oito das 11 ordens propostas por Smith et al. (2006), com exceção apenas de Salviniales, Osmundales e Equisetales, além de cinco espécies de licófitas, distribuídas em três gêneros e duas famílias, representando duas das três ordens que compõem a Divisão (exceto Isoetales).

\section{Tratamento Taxonômico}

\section{Chave de identificação para as famílias}

1. Plantas com microfilos.

2. Plantas homosporadas; microfilos não ligulados, arranjados em espiral Lycopodiaceae

2'. Plantas heterosporadas; microfilos ligulados, arranjados em duas fileiras dorsais e duas laterais. Selaginellaceae 1'. Plantas com megafilos.

3. Esporângios com paredes pluriestratificadas, reunidos entre si, formando sinângios.

4. Sinângios axilares; eixos aéreos furcados dicotomicamente.

Psilotaceae

4'. Sinângios dispostos na base ou na face abaxial da lâmina; eixos aéreos não furcados dicotomicamente.

5. Sinângios longo-pedunculados, em forma de espiga, dispostos dorsalmente na base da lâmina; lâmina palmatilobada; nervuras anastomosadas.

5'. Sinângios sésseis, lineares, dispostos na face abaxial da lâmina; lâmina 1-pinada; nervuras livres

Ophioglossaceae

Marattiaceae

3'. Esporângios com paredes uniestratificadas, isolados, não formando sinângios.

6. Esporângios sésseis ou subsésseis; ânulo não interrompido pelo pedicelo.

7. Tecido laminar com uma camada de célula de espessura (exceto nas nervuras), raramente mais de uma, estômatos ausentes; soros marginais protegidos por indúsio tubular ou bivalvar.

Hymenophyllaceae

7’. Tecido laminar com várias camadas de células de espessura, estômatos presentes; soros abaxiais, quando marginais nunca apresentando indúsio tubular nem bivalvar.

8. Lâmina com divisão pseudodicotômica e com gemas nas bifurcações.

Gleicheniaceae

8'. Lâmina não pseudodicotomicamente dividida, sem gemas nas bifurcações.

9. Esporângios com ânulo oblíquo.

9'. Esporângios com ânulo apical.

Cyatheaceae

10. Esporângios em um par de pinas proximal modificado.

10 '. Esporângios nas margens modificadas dos segmentos.

11. Frondes volúveis com crescimento indeterminado.

Anemiaceae

11 '. Frondes não volúveis com crescimento determinado.

Lygodiaceae

Schizaeaceae

6'. Esporângios pedicelados com o ânulo vertical interrompido pelo pedicelo.

12. Base do estípite com dois feixes vasculares.

13. Soros arredondados ou alongados; feixes vasculares da raque em forma de "U"

13 '. Soros elípticos ou lineares; feixes vasculares da raque em forma de " $X$ ".

$12^{\prime}$. Base do estípite com um, três ou mais feixes vasculares.

14. Soros paralelos à costa; indúsios abrindo-se em direção à costa.

14'. Soros não paralelos à costa; indúsios abrindo-se de outras formas ou ausentes.

15. Rizoma com tricomas.

15'. Rizoma com escamas

16. Soros na margem dos segmentos, sem indúsio, neste caso localizados em sulcos na lâmina, ou protegidos por um pseudoindúsio, formado pela margem revoluta dos segmentos.

Pteridaceae

16'. Soros com outra disposição ou quando marginais não localizados em sulcos, sem indúsio ou protegidos por indúsio verdadeiro.

17. Indúsio linear ou cupuliforme, abrindo-se em direção à margem.

18. Pinas ou pínulas dimidiadas; soros alongados, localizados na margem distal...Lindsaeaceae

18'. Pinas oblongo-elípticas; soros arredondados a cônicos, localizados na margem distal proximal.

Saccolomataceae 
17'. Indúsio ausente ou com outras formas, abrindo-se em várias direções.

19. Soros sem indúsio, bem delimitados, lineares, arredondados ou oblongos

Polypodiaceae

19'. Soros com ou sem indúsio, neste caso formando cenossoros ou com esporângios distribuídos em toda a face abaxial da lâmina (acrosticoides).

20. Pinas articuladas.

Lomariopsidaceae

20'. Pinas contínuas à raque.

21. Estípite com feixes vasculares dispostos em um único círculo em corte transversal........

21'. Estípite com vários feixes vasculares circulares, dispostos em anel.

Tectariaceae

Dryopteridaceae

\section{Anemiaceae}

1. Lâmina 1-pinado-pinatífida.

1'. Lâmina 1-pinada.

2. Pina apical conforme; nervuras anastomosadas

Anemia phyllitidis

2'. Pina apical não conforme; nervuras livres.

3. Lâmina deltoide com tricomas curtos, alvacentos; pinas oblíquas basioscopicamente e arredondadas acroscopicamente.

Anemia hirta

3'. Lâmina linear-lanceolada com tricomas longos, castanhos; pinas subdimidiadas.

Anemia mandiocana

\subsection{Anemia hirta (L.) Sw., Syn. Fil.: 155. 1806.}

Terrestre na borda da mata e como rupícola próxima a córrego, em local sombreado, a ca. 620 m s.n.m. Caracteriza-se por apresentar a lâmina 1-pinada, ápice pinatífido, esparsamente vilosa, base das pinas desigual, obliqua basioscopicamente e arredondada acroscopicamente, nervuras livres.

Distribuição. Do México à América do Sul. No Brasil: CE, PE, AL, BA, MG e ES.

\subsection{Anemia mandioccana Raddi, Opusc. Sci. Bol. 3: 282.} 1819.

Figura 1.

Rupícola no interior da mata, a 620-780 m s.n.m. Caracteriza-se pela lâmina linear-lanceolada, 1-pinada, base das pinas desigual, truncada acroscopicamente, subdimidiada, cuneada basioscopicamente, nervuras livres. Pode ser confundida com $A$. radicans Raddi (Casarino et al. 2009), da qual se distingue por não possuir a raque prolífera, pinas mais estreitas e agudas e pecíolo glabro na base (vs. pinas obtusas e pecíolo piloso em $A$. radicans).

Distribuição. Restrita à Mata Atlântica brasileira: BA, MG, ES, RJ e SP.

\subsection{Anemia phyllitidis (L.) Sw., Syn. Fil.: 155. 1806.} Figura 2.

Terrestre, na borda ou no interior da mata, a ca. $700 \mathrm{~m}$ s.n.m. É facilmente distinguida pela lâmina 1-pinada, ápice conforme, pinas lanceoladas e nervuras totalmente anastomosadas. Segundo Assis (2007), assemelha-se a A. herzogii Rosenst., a qual apresenta pinas obovais a ovallanceoladas (vs. pinas oblongo-lanceoladas com ápice acuminado em $A$. phyllitidis) e nervuras anastomosadas próximo à costa, tornando-se livres nas proximidades da margem.

Distribuição. Do sul do México à América do Sul. Amplamente distribuída no Brasil: AM, MT, GO, DF, CE, PE, AL, BA, MG, ES, RJ, SP, PR, SC e RS.

1.4. Anemia villosa Humb. \& Bonpl. ex Willd., Sp. Pl., ed. 4 [Willdenow] 5: 92. 1810.

Figura 3.

Comum na área de estudo, ocorrendo como terrestre ou rupícola, principalmente em barranco na borda da mata, local ensolarado ou parcialmente exposta ao sol, a ca. $750 \mathrm{~m}$ s.n.m. Caracteriza-se pela lâmina lanceolada a deltoide, 1pinado-pinatífida, ápice pinatífido, vilosa, pinas com base obtusa a truncada. Segundo Ferreira (2009), variações consideráveis no tamanho e forma da lâmina de Anemia villosa podem fazer com que ela seja confudida com outras espécies, como A. flexuosa (Savigny) Sw., por exemplo. Tryon \& Stolze (1989a) ressaltam que estas espécies parecem diferir apenas quantitativamente, com pinas estéreis mais fortemente dissecadas e pina fértil mais curta do que a porção estéril em A. flexuosa e pinas férteis geralmente mais longas ou iguais a lâmina estéril em $A$. villosa.

Distribuição. América do Sul. No Brasil, ocorre no domínio da Floresta Atlântica: CE a SC.

\section{Aspleniaceae}

1. Lâmina inteira

1'. Lâmina 1-pinada. Asplenium serratum

2. Pinas auriculadas acroscopicamente, sobrepostas à raque; pina apical não conforme

Asplenium auriculatum

2'. Pinas não auriculadas, não sobrepostas à raque; pina apical conforme Asplenium feei

2.1. Asplenium auriculatum Sw., Kongl. Vetensk. Acad. Handl. 1817(1): 68. 1817.

Epífita na borda ou interior da mata, em local sombreado, sendo muito comum na área de estudo, a ca. 700 m s.n.m. Caracteriza-se pela lâmina 1-pinada, com pinas auriculadas 
no lado acroscópico, sobrepondo a raque, e margem serreada. É próxima de A. salicifolium L. (Sylvestre 2001), porém possui folhas menores (lâmina 6-15 × 2,5-6 cm), nervuras simples ou 1-furcadas, soros curtos, medianos, 3-6 no lado acroscópico e 2-5 no basiscópico (vs. lâmina 12-35 × 7-15 $\mathrm{cm}$, a maioria das nervuras 2-furcadas, soros longos, aproximados da costa, 9-15 no lado acroscópico e 10-13 no basiscópico em $A$. salicifolium).

Distribuição. Do México à América do Sul. No Brasil: RR, MS, PE, BA, MG, ES, RJ, SP, PR, SC e RS.

2.2. Asplenium feei Kunze ex Fée, Mém. Foug. 5: 194. 1852. Figura 4.

Epífita, ocorrendo no interior da mata, a ca. $780 \mathrm{~m}$ s.n.m. Caracteriza-se pela pina apical conforme, consistência coriácea, coloração escura quando seca, indúsios coriáceos com as laterais curvas em relação à nervura (Sylvestre 2001).

Distribuição. Do México à América do Sul. No Brasil: RR, CE, BA, MG, ES, RJ, SP, PR e SC.

\subsection{Asplenium serratum L., Sp. Pl. 2: 1079. 1753.} Figura 5.

Epífita, encontrada no interior da mata, a ca. 660 m s.n.m. Caracteriza-se pela lâmina inteira, lanceolada, ápice acuminado, margem subinteira a serreada. Assemelha-se a Asplenium angustum Sw.; porém, segundo Sylvestre (2001), difere desta por apresentar a lâmina com ápice acuminado, nervuras obtusas, formando um ângulo de $60^{\circ}-75^{\circ}$, soros atingindo $1 / 2-2 / 3$ da distância entre a costa e a margem (vs. lâmina com ápice longo-atenuado, nervuras formando um ângulo de $30^{\circ}-50^{\circ}$, soros ca. $3 / 4$ da distância entre a costa e a margem em $A$. angustum).

Distribuição. Do México à América do Sul. No Brasil: RR, AP, AM, PA, AC, RO, MT, MS, GO, MA, CE, PB, PE, AL, BA, MG, ES, RJ, SP, PR e SC.

\section{BLEChNaCEAe}

1. Planta com hábito escandente.......Salpichlaena volubilis

1'. Planta com hábito herbáceo ou subarborescente.

2. Lâmina reduzida na base; pinas com margem serreada. Blechnum brasiliense

2'. Lâmina não reduzida na base; pinas com margem inteira. Blechnum occidentale

3.1. Blechnum brasiliense Desv., Ges. Naturf. Freunde Berlin Mag. Neuesten Entdeck. Gesammten Naturk. 5:330. 1811.

Figura 6.

Terrestre, em local sombreado, bastante úmido, próximo ao córrego, a ca. 680 m s.n.m. Diferencia-se de Blechnum occidentale pelo hábito subarborescente e pinas com margem serreada. Segundo Dittrich (2005), é semelhante a $B$. spannagelii Rosenst. quando estéril. Esta última é endêmica das Regiões Sudeste e Sul e pode ser distinguida de $B$. brasiliense por apresentar a margem das pinas inteira e escamas do caule castanho-claras a escuras (vs. margem das pinas serreada e escamas do caule nigrescentes em $B$. brasiliense). Quando férteis são facilmente diferenciadas, pois $B$. spannagelii apresenta dimorfismo foliar.

Distribuição. Guatemala, Venezuela, Colômbia, Equador, Peru, Bolívia, Paraguai, Argentina, Uruguai e Brasil (MT, MS, DF, CE, BA, MG, ES, RJ, SP, PR, SC e RS).

\subsection{Blechnum occidentale L., Sp. Pl. 2: 1077. 1753.}

Terrestre, ocorrendo em local sombreado na borda ou interior da mata, em terreno plano ou íngreme, a ca. $730 \mathrm{~m}$ s.n.m. Caracteriza-se pelas pinas basais completamente livres, não reduzidas, lanceolado-falcadas. É próxima de $B$. austrobrasilianum. Difere desta principalmente pelas pinas basais, que são completamente livres e quase perpendiculares ao plano longitudinal da raque (vs. pinas adnatas à raque no lado acroscópico e praticamente paralelas ao plano longitudinal em B. austrobrasilianum; Dittrich 2005).

Distribuição. Amplamente distribuída na América tropical, dos Estados Unidos à Argentina. No Brasil: RR, MT, MS, GO, CE, PE, BA, MG, ES, RJ, SP, PR, SC e RS.

\subsection{Salpichlaena volubilis (Kaulf.) J.Sm., J. Bot. (Hooker)} 4: 168.1841.

Figura 7.

Terrestre, em local sombreado, úmido, a ca. $620 \mathrm{~m}$ s.n.m. Caracteriza-se pelo hábito escandente, frondes 2-pinadas, pínulas linear-lanceoladas, ápice acuminado. O gênero é endêmico da América, sendo representado somente por Salpichlaena volubilis e $S$. hookeriana Alston. Esta última ocorre na Guiana, Guiana Francesa, Suriname, Venezuela, Colômbia e Norte do Brasil até o Peru e a Bolívia. Os principais caracteres distintivos entre as espécies são a largura da lâmina das pínulas férteis, sendo bastante reduzida em $S$. hookeriana e mais larga em $S$. volubilis, além das gemas na base das pínulas estéreis presentes na primeira espécie mas ausente na segunda (Giudice et al. 2008).

Distribuição. Amplamente distribuída na América Central e América do Sul. No Brasil: AM, MT, CE, PE, BA, MG, RJ, SP e SC.

\section{Cyatheaceae}

1. Soros com indúsio.

1'. Soros sem indúsio.

2. Pinas e pínulas articuladas, as apicais conformes Cyathea corcovadensis

2'. Pinas e pínulas não articuladas, as apicais não conforme, ápice gradual ou abruptamente reduzido.

3. Base do estípite sem espinhos; lâmina abruptamente reduzida em direção ao ápice...... Cyathea nigra

3'. Base do estípite com espinhos; lâmina gradualmente reduzida em direção ao ápice.

4. Escamas do estípite com margens fimbriadas; pínulas com ápice atenuado; indumento hirsuto com tricomas ausentes a raros e escâmulas planas.

Cyathea abreviata 
4'. Escamas do estípite sem margens fimbriadas; pínulas com ápice agudo; indumento viloso a hirsuto com escâmulas buladas e tricomas presentes na costa, cóstulas, nervuras e tecido laminar.

Cyathea phalerata

4.1. Cyathea abreviata I.Fern., Bradea 8(31): 193. 2000. Figuras 8 e 9.

Terrestre, frequente na área de estudo, ocorrendo na borda ou interior da mata, em local sombreado ou parcialmente ensolarado, terreno plano ou íngreme, a ca. $800 \mathrm{~m}$ s.n.m. Caracteriza-se pelo estípite com espinhos escuros e finos, pínulas profundamente incisas com ápices geralmente atenuados, principalmente na porção apical das frondes, indumento de aspecto setuloso (abundante ou raro) na face abaxial, caracterizado pela ausência ou escassez de escâmulas buladas ou tricomas e costa nigrescente no material herborizado (Fernandes 2003). Segundo Fernandes (2003), assemelha-se a $C$. nigripes (C.Chr.) Domin, espécie distribuída desde a Costa Rica até o Peru. Esta última difere por possuir as escamas da base dos pecíolos e pínulas maiores [0,8-1,4 cm e (3-)4-10,5 cm, respectivamente, em $C$. abreviata], costa e cóstula sem indumento setuloso e soros com paráfises mais curtas que os esporângios (vs. paráfises iguais ou mais longas que os esporângios em C. abreviata).

Distribuição. Endêmica da Região Nordeste: CE, PE, AL e BA.

4.2. Cyathea corcovadensis (Raddi) Domin, Pteridophyta: 262. 1929.

Terrestre, ocorrendo no interior da mata, a 600-700 m s.n.m. Caracteriza-se principalmente pela lâmina 2-pinada, com pinas articuladas à raque e pina apical conforme. Segundo Fernandes (1997), pode apresentar grande variação nos recortes das pínulas (inteira, crenulada, serreada, lobada ou pinatífida), sendo muitas vezes observada em diferentes partes da fronde. Espécimes com ápice das pinas lobado, pínulas pequenas com bordo crenulado e textura coriáceorija assemelham-se a C. dichromatolepis (Fée) Domin, diferindo pelas escamas do pecíolo concolores, castanho-claras, pinas oblongas, patentes, articuladas à raque (vs. escamas do pecíolo bicolores, alvacentas na margem e castanho-escuras no centro, pinas lanceoladas, ascendentes, não articuladas em $C$. dichromatolepis).

Distribuição. Endêmica do Brasil: AL, BA, MG, ES, RJ, SP, PR, SC e RS.

4.3. Cyathea delgadii Sternb., Vers. Fl. Vorwelt 1: 47; tab. B. 1820 .

Terrestre, encontrada próximo a córrego, em local parcialmente exposto ao sol, a ca. 700 m s.n.m. Caracteriza-se pelo caule com cicatrizes foliares (nos indivíduos adultos), lâmina 2-pinado-pinatífida com escâmulas planas e triangulares, soros medianos, indúsio globoso. Segundo Fernandes (1997), apresenta ampla variação morfológica. Entretanto, espécimes férteis podem ser facilmente reconhecido por apre- sentarem o indúsio globoso.

Distribuição. Costa Rica, Panamá, Trindade, Guiana até Bolívia, Paraguai e Brasil (RR, MT, MS, GO, DF, PI, CE, PE, BA, MG, ES, RJ SP, PR, SC e RS).

4.4. Cyathea nigra Linden ex Fournet, Ill. Hort. 23: 73; tab. 242. 1876.

Terrestre, encontrada no interior da mata, a ca. $800 \mathrm{~m}$ s.n.m. Caracteriza-se pelo estípite sem espinhos, com escamas marginadas, lâmina e pinas abruptamente reduzidas em direção ao ápice (Prado \& Freitas 2005). Segundo Labiak \& Matos (2009), assemelha-se a C. atrocastanea Labiak \& F.B.Matos, espécie endêmica do Espírito Santo, mas difere desta pela costa, cóstula e nervuras com tricomas abaxialmente, escamas linear-lanceoladas na costa, segmentos crenulados e lâmina abruptamente reduzida em direção ao ápice (vs. costa, cóstula e nervuras glabras abaxialmente, escamas ovais a lanceoladas, segmentos com margem inteira e lâmina gradualmente reduzida no ápice em $C$. atrocastanea).

Distribuição. Era conhecida no Brasil apenas para a região da Bacia Amazônica (Zuquim et al. 2008), nos estados do Amazonas e Bahia.

4.5. Cyathea phalerata Mart., Denkschr. Bayer. Bot. Ges.

Regensberg. 2: 146; tab. 2, fig. 3. 1822.

Terrestre, ocorrendo no interior da mata, a ca. $660 \mathrm{~m}$ s.n.m. Caracteriza-se pelo caule com restos das bases de estípites persistentes, ápice das pínulas acuminado, caudado ou obtuso e face abaxial da costa e cóstula com escâmulas buladas, em geral alvacentas ou estramíneas, abundantes e escâmulas planas, lanceoladas, ferrugíneas.

Distribuição. Endêmica do Brasil: MT, GO, DF, CE, PB, PE, AL, BA, MG, ES, RJ, SP, PR, SC e RS.

\section{Dennstaedtiaceae}

1. Soros arredondados; indúsio verdadeiro com porção adaxial e abaxial presente somente nos segmentos férteis. Dennstaedtia dissecta

1'. Soros lineares; pseudoindúsio formado pela margem revoluta dos segmentos, o adaxial presente também nos segmentos estéreis.

Pteridium arachnoideum

\subsection{Dennstaedtia dissecta (Sw.) T.Moore, Ind. Fil.: 305.} 1861.

Terrestre, no interior da mata, a ca. 440 m s.n.m. Caracteriza-se pelas pínulas basais reduzidas, comumente com gemas axilares e lâmina 3-pinado-lobada. É semelhante a $D$. obtusifolia (Willd.) T.Moore e D. cornuta (Kaulf.) Mett. Diferencia-se da primeira por apresentar a lâmina 3-pinadolobada, com os últimos segmentos oblongos, de ápice truncado-denticulado (vs. lâmina 2-pinado-pinatífida, com os últimos segmentos oblongos, de ápice arredondado e crenado). Distingue-se de $D$. cornuta por apresentar rizoma prostrado, com raízes abundantes na base do estípite, e pela 
menor dissecção da lâmina (vs. rizoma ascendente, com ápice elevado, poucas raízes na base do estípite e lâmina 3-pinadopinatífida a 4-pinada; Navarrete \& Øllgaard 2000).

Distribuição. América Central e América do Sul. No Brasil, ocorre no domínio da Floresta Atlântica, com registro para as Regiões Nordeste, Sudeste e Sul.

\subsection{Pteridium arachnoideum (Kaulf.) Maxon, J. Wash.} Acad. Sci. 14: 89. 1924.

\section{DRYOPTERIDACEAE}

1. Frondes monomorfas.
Terrestre, ocorrendo em local ensolarado, formando densas populações, a ca. $700 \mathrm{~m}$ s.n.m. Caracteriza-se por apresentar lâmina coriácea, 3- ou 4-pinada e lobos livres entre os últimos ou penúltimos segmentos próximos ao ápice das pinas.

Distribuição. Do México à América do Sul. No Brasil, encontra-se amplamente distribuída, ocorrendo nos domínios da Floresta Amazônica, Cerrado, Pantanal, Floresta Atlântica e Pampa, do Amazonas ao Rio Grande do Sul.

2. Rizoma reptante; lâmina 3-pinado-pinatífida Rumohra adiantiformis

2'. Rizoma decumbente a ereto; lâmina 1-pinado-pinatífida ou 2-pinada.

3. Lâmina 2-pinada, pínulas subdimidiadas; soros elípticos Didymochlaena truncatula

3'. Lâmina 1-pinado-pinatífida, pinas lanceoladas; soros arredondados.

4. Nervuras 10-15 pares por segmento; soros inframedianos. Ctenitis distans

4'. Nervuras 6-8 pares por segmento; soros medianos ou supramedianos Ctenitis falciculata

1 '. Frondes dimorfas.

5. Lâmina 1-pinada ou mais vezes dividida.

6. Soros arredondados, indúsio peltado..

6'. Soros acrosticoides, sem indúsio.

7. Pinas articuladas à raque; nervuras anastomosadas

7’. Pinas não articuladas; nervuras livres.

8. Lâmina 1-pinada; nervuras conectadas a uma nervura marginal coletora

8'. Lâmina 2-pinado-pinatífida; nervuras não conectadas a uma nervura coletora.

5'. Lâmina inteira.

9. Lâmina com escamas conspícuas ao longo da nervura mediana e margens.

9'. Lâmina glabra ou com diminutas escamas estreladas, esparsas e inconspícuas.

10. Nervuras geralmente livres, com algumas anastomosando-se nas margens ... Elaphoglossum macrophyllum 10 . Nervuras livres até a margem.

11. Rizoma decumbente a ereto

Elaphoglossum luridum

11'. Rizoma reptante.

12. Lâmina estéril oval-oblonga com ápice obtuso

Elaphoglossum lingua

12'. Lâmina estéril sem a forma anterior e com ápice acuminado ou agudo.

13. Lâmina linear-lanceolada.

14. Lâmina estreita, ca. 1 cm larg., glabra..

Elaphoglossum glabellum

14'. Lâmina 2-4 cm larg., com escamas estreladas, diminutas..... Elaphoglossum pachydermum 13'. Lâmina lanceolada, oblonga, oblongo-lanceolada ou oval-lanceolada

15. Lâmina lanceolada, base decorrente, estípite até $12 \mathrm{~cm}$ compr..... Elaphoglossum iguapense

15'. Lâmina oblongo ou oval-lanceolada, base pouco decorrente, estípite mais longo.

\section{Lâmina oblongo-lanceolada, diminuindo gradualmente para as duas extremidades}

Elaphoglossum itatiayense 16'. Lâmina oval-lanceolada acuminada, base abruptamente atenuada...Elaphoglossum vagans

6.1. Ctenitis distans (Brack.) Ching, Bull. Fan Mem. Inst. Biol. Bot. 8: 277. 1938.

Figura 10.

Terrestre, comum na área de estudo. Ocorre desde a borda até o interior da mata, sempre em local sombreado, em terreno plano ou íngreme, a ca. $700 \mathrm{~m}$ s.n.m. Caracteriza-se pela lâmina 1-pinado-pinatífida, 10-15 nervuras nos segmentos, escamas da raque marrom-escuras a negras, rígidas, soros inframedianos. Apresenta morfologia intermeSitientibus série Ciências Biológicas 12(2): 269-291. 2012. diária entre C. falciculata e C. submarginalis (Langsd. \& Fisch.) Ching. Difere da primeira pelas características apresentadas na chave e da segunda por apresentar as escamas da raque escuras, com células de paredes rígidas, indúsio conspícuo e persistente (vs. escamas da raque vermelhoamareladas, com células de paredes finas, indúsio inconspícuo ou ausente; Christensen 1913).

Distribuição. Endêmica do Brasil: AL, PE, BA, MG, RJ, SP e PR. 
6.2. Ctenitis falciculata (Raddi) Ching, Sunyatsenia 5(4): 250. 1940

Terrestre, encontrada no interior da mata, a ca. $750 \mathrm{~m}$ s.n.m. Caracteriza-se pela lâmina 1-pinado-pinatífida, 6-8 nervuras por segmento, soros medianos ou supramedianos. Assemelha-se a Ctenitis distans e C. submarginalis (Langsd. $\&$ Fich.) Ching. (ver comentário anterior).

Distribuição. Guiana e Brasil (PB, BA, MG, SP, RJ, PR e SC).

\subsection{Cyclodium meniscioides (Willd.) C.Presl, Tent. Pterid.:} 85. 1836.

Figura 11.

Terrestre ou rupícola, ocorrendo no interior da mata, próximo a córrego, em local bastante úmido, a ca. $700 \mathrm{~m}$ s.n.m. Caracteriza-se pelas frondes subdimorfas a dimorfas, lâmina pinada com ápice conforme, pinas estéreis com margem inteira ou sinuosa, pinas férteis com margem sinuosa ou crenada, indúsio peltado, ciliado. Segundo Smith (1986), é a espécie mais amplamente distribuída e mais variável do gênero, podendo apresentar, por exemplo, variações das pinas estéreis e férteis no mesmo indivíduo, o que indica a facilidade com que essa espécie assume diferentes formas de desenvolvimento.

Distribuição. Trinidad, Colômbia, Guiana, Guiana Francesa, Suriname, Venezuela, Equador, Peru, Bolívia, Paraguai, Argentina e Brasil (AP, AM, PA, AC, TO, MT, MS, GO, DF, PI, CE, PE, BA, MG, ES e SP).

6.4. Didymochlaena truncatula (Sw.) J.Sm., J. Bot. (Hooker) 4: 196. 1841.

Figura 12.

Terrestre, econtrada no interior da mata, a ca. $790 \mathrm{~m}$ s.n.m. Caracteriza-se pela lâmina 2-pinada, pínulas subdimidiadas, articuladas, soros de formato elíptico.

Distribuição. Pantropical. No Novo Mundo, ocorre no México, América Central, Antilhas, Guiana, Guiana Francesa, Suriname, Venezuela, Colômbia, Equador, Peru, Bolívia, Paraguai, Argentina e Brasil (RR, AM, AC, AL, PE, BA, MG, ES, RJ, SP, PR, SC e RS).

6.5. Elaphoglossum glabellum J.Sm., London J. Bot. 1: 197. 1842.

Epífita, a ca. 780 m s.n.m. Caracteriza-se pelo rizoma curto-reptante, com escamas castanho-escuras a negras, frondes linear-lanceoladas, com margem revoluta, frondes férteis menores que as estéreis, lâmina coriácea, acuminada nas extremidades.

Distribuição. México, Costa Rica, Panamá, Antilhas, Guiana, Suriname, Venezuela, Colômbia, Equador, Peru, Bolívia e Brasil (AM, MG, GO, PE, BA, RJ e SP).

6.6. Elaphoglossum iguapense Brade, Arq. Inst. Biol. Veg. 3: 6. 1936.

Epífita, no interior da mata, a ca 700 m s.n.m. Caracte- riza-se pela lâmina estéril lanceolada, atenuada para as duas extremidades, base decorrente, subcoriácea, com pequenas escamas estreladas na face abaxial, lâmina da fronde fértil menor e mais estreita.

Distribuição. Endêmica do Brasil: BA (primeiro registro), MG, SP, PR, SC e RS.

6.7. Elaphoglossum insigne (Fée) Brade, Bol. Parque Nacion. Itatiaia ser. Tecn.-sc. 5: 56. 1956.

Figuras 13 e 14.

Epífita, a ca. 750 m s.n.m. Caracteriza-se pelo estípite com escamas subuladas, patentes, lâmina com escamas ovais e imbricadas na margem, escamas diminutas, estreladas, esparsamente distribuídas no tecido laminar e nervura mediana com escamas iguais as do estípite.

Distribuição. Endêmica do Brasil: BA, RJ, SP e PR.

6.8. Elaphoglossum itatiayense Rosenst., Hedwigia 56: 370. 1915.

Epífita, no interior da mata, a ca. 770 m s.n.m. Caracteriza-se pelo rizoma rastejante, lâmina estéril oblongolanceolada, subcoriácea, acuminada nas extremidades; fronde fértil mais estreita e com estípite maior que o da estéril.

Distribuição. Endêmica do Brasil: BA (primeiro registro), MG, RJ, SP e SC.

6.9. Elaphoglossum lingua Brack., U.S. Expl. Exp., Filic. 16: 74.1854.

Epífita no interior da mata, a ca. 730 m s.n.m. Caracteriza-se pelo rizoma longo-reptante, com escamas negras, dispersas, lâmina oval a oblonga, coriácea, arredondada no ápice.

Distribuição. México, Antilhas, Costa Rica, Panamá, Guiana Francesa, Venezuela, Colômbia, Equador, Peru, Chile, Bolívia, Paraguai e Brasil (DF, PE, BA, MG, RJ, SP, PR e SC).

6.10. Elaphoglossum luridum (Fée) Christ, Neue Denkschr. Allg. Schweiz. Ges. Gesammten Naturwiss 36(1): 33.1899.

Epífita, encontrada no interior da mata, a ca. 770 m s.n.m. Caracteriza-se pelo rizoma decumbente a ereto, lâmina estéril oblongo-elíptica, base decorrente, coriácea, com escamas negras na face abaxial, dispostas principalmente sobre a nervura central.

Distribuição. Costa Rica, Panamá, Trinidad, Guiana, Guiana Francesa, Suriname, Venezuela, Colômbia, Equador, Peru, Bolívia e Brasil (RR, AM, PA, BA, MG, RJ, SP, PR, SC e RS).

\subsection{Elaphoglossum macrophyllum (Mett.) Christ, Bull.}

Herb. Boisser, sér. 2, 5(1): 10. 1905.

Epífita no interior da mata, a ca. $770 \mathrm{~m}$ s.n.m. Caracteriza-se pelo estípite longo, lâmina oblonga, acuminada nas duas extremidades, coriácea, nervuras geralmente livres, al- 
gumas anastomosando-se perto da margem.

Distribuição. Venezuela, Equador, Bolívia e Brasil (BA, MG, RJ, SP, PR, SC e RS).

\subsection{Elaphoglossum pachydermum (Fée) Moore, Ind. Fil.:} 12. 1857.

Epífita, rupícola ou terrestre, encontrada da borda ao interior da mata, em local sombreado, a ca. 780 m s.n.m. Caracteriza-se pelo rizoma reptante, lâmina linearlanceolada, atenuada para as duas extremidades, coriácea, com pequenas escamas estreladas na face abaxial.

Distribuição. Endêmica do Brasil: DF, BA, MG, RJ, PR, SC e RS.

\subsection{Elaphoglossum vagans (Mett.) Hieron., Bot. Jahrb.}

Syst. 34: 543. 1904.

Epífita, encontrada no interior da mata, a ca. 780 m s.n.m. Caracteriza-se pelo rizoma longo-reptante, moderadamente coberto por escamas castanho-claras, lâmina oval a ovallanceolada, coriácea, base obtusa, ápice acuminado. Segundo Novelino \& Oliveira (1999), apresenta ampla variação morfológica, sendo próxima de E. itatiayense Rosenst, que difere pelo pecíolo mais longo na fronde estéril (23,5-33 cm vs. 9-34 cm compr.) e a lâmina com nervuras mais evidentes. Ainda assim, a separação destas espécies por características morfológicas não é fácil.

Distribuição. Endêmica do Brasil: BA, MG, ES, RJ, SP, PR, SC e RS.

6.14. Mickelia guianensis (Aubl.) R.C.Moran, Sundue \& Labiak., Brittonia 62: 345. 2010.

Hemiepífita, a ca. 680 m s.n.m. Caracteriza-se pelo caule longo-reptante esparsamente escamoso, frondes dimorfas, lâmina 1-pinada, pinas articuladas, nervuras anastomosadas. É a única espécie do gênero na região neotropical. Pode ser confundida com espécies do gênero Bolbitis Schott com lâmina 1-pinada devido, principalmente, ao padrão de nervuras da lâmina, porém se diferencia delas pelas pinas articuladas à raque (vs. pinas contínuas ou não articuladas).

Distribuição. Grandes Antilhas (exceto Jamaica), Guiana, Guiana Francesa, Suriname, Venezuela, Colômbia, Equador, Peru, Bolívia, Argentina e Brasil (AP, AM, PE, BA, RJ, SP, PR, SC e RS).

\subsection{Olfersia cervina (L.) Kunze, Flora 7: 312. 1824.}

Figuras 15 e 16.

Terrestre, encontrada no interior da mata, a ca. $790 \mathrm{~m}$ s.n.m. Caracteriza-se pelas frondes dimorfas, a estéril pinada com pinas inteiras e ápice conforme, nervuras furcadas, paralelas, conectando-se a uma nervura submarginal, a lâmina fértil pode se apresentar de duas formas: pinas inteiras e esporângios em ambas as faces ou pinas pinatífidas e esporângios apenas na face abaxial. Olfersia Raddi é morfologicamente similar a Polybotrya Humb. \& Bonpl. ex Willd., podendo ser diferenciada pelas características apre- sentadas acima. Polybotrya apresenta lâmina estéril com ápice pinatífido, nervuras de diferentes padrões, nunca se unindo a uma nervura submarginal; e, principalmente, pela anatomia do caule: em Olfersia cada meristelo é circundado por células paranquimatosas esbranquiçadas e o arranjo dos mesmos é irregular, enquanto em Polybotrya ocorre uma bainha escura de fibras esclerenquimáticas e o arranjo é uniforme e circular (Moran 1986).

Distribuição. Sul do México, América Central, Antilhas, Guiana, Guiana Francesa, Suriname, Venezuela, Colômbia, Equador, Peru, Bolívia e Brasil (AM, PA, RO, MT, MS, GO, CE, PE, AL, BA, MG, ES, RJ, SP, PR, SC e RS).

6.16. Polybotrya speciosa Schott, Gen. Fil.: tab. 7. 1834. Figuras 17 e 18.

Hemiepífita, ocorrendo na borda ou interior da mata, a ca. 770 m s.n.m., sendo frequente na área de estudo. Caracteriza-se pelas escamas do caule avermelhadas, fortemente denticuladas, lâmina finamente dividida e paráfises multicelulares, ramificadas. De acordo com Moran (1987), Polybotrya speciosa e $P$. pilosa Brade são as únicas espécies do gênero que possuem paráfises ramificadas e podem ser distinguidas pela presença de tricomas menores que 1 $\mathrm{mm}$ compr., algumas vezes tortuosos, tanto nos eixos como no tecido laminar da primeira espécie (vs. tricomas maiores que $1 \mathrm{~mm}$ compr., aciculares, sobre as nervuras na segunda). Contudo, o autor também relata que mais raramente os tricomas de $P$. pilosa podem aparecer na superfície laminar e ressalta que essas duas espécies podem ser assunto para estudos futuros. Garcia \& Salino (2009), ao estudarem materiais provenientes da Região Sudeste, apontam a presença de variações com relação à posição, densidade e tamanho dos tricomas, não sustentando a separação destas espécies apenas com base no indumento.

Distribuição. Endêmica da Floresta Atlântica brasileira: BA, MG, RJ e SP.

6.17. Rumohra adiantiformis (G.Forst.) Ching, Sinensia 5: 70. 1934.

Epífita, no interior da mata, a ca. 650 m s.n.m. Caracteriza-se pela lâmina com contorno deltoide, pinas pecioluladas, segmentos denticulados, indúsio peltado, caduco, deixando uma cicatriz da fixação após queda. Segundo Labiak \& Prado (1998), é uma espécie extremamente variável quanto à morfologia (tamanho e consistência da fronde, intensidade do indumento e divisão da lâmina) devido à grande amplitude de ambientes e hábitos apresentados pela mesma.

Distribuição. Pantropical. No Brasil: MS, BA, MG, RJ, SP, PR, SC e RS.

\section{Gleicheniaceae}

1. Rizoma e gema axilar das furcas com escamas; nervuras simples a 1-furcadas. Sticherus bifidus

1 '. Rizoma e gema axilar das furcas com tricomas; nervuras 1-4-furcadas. 

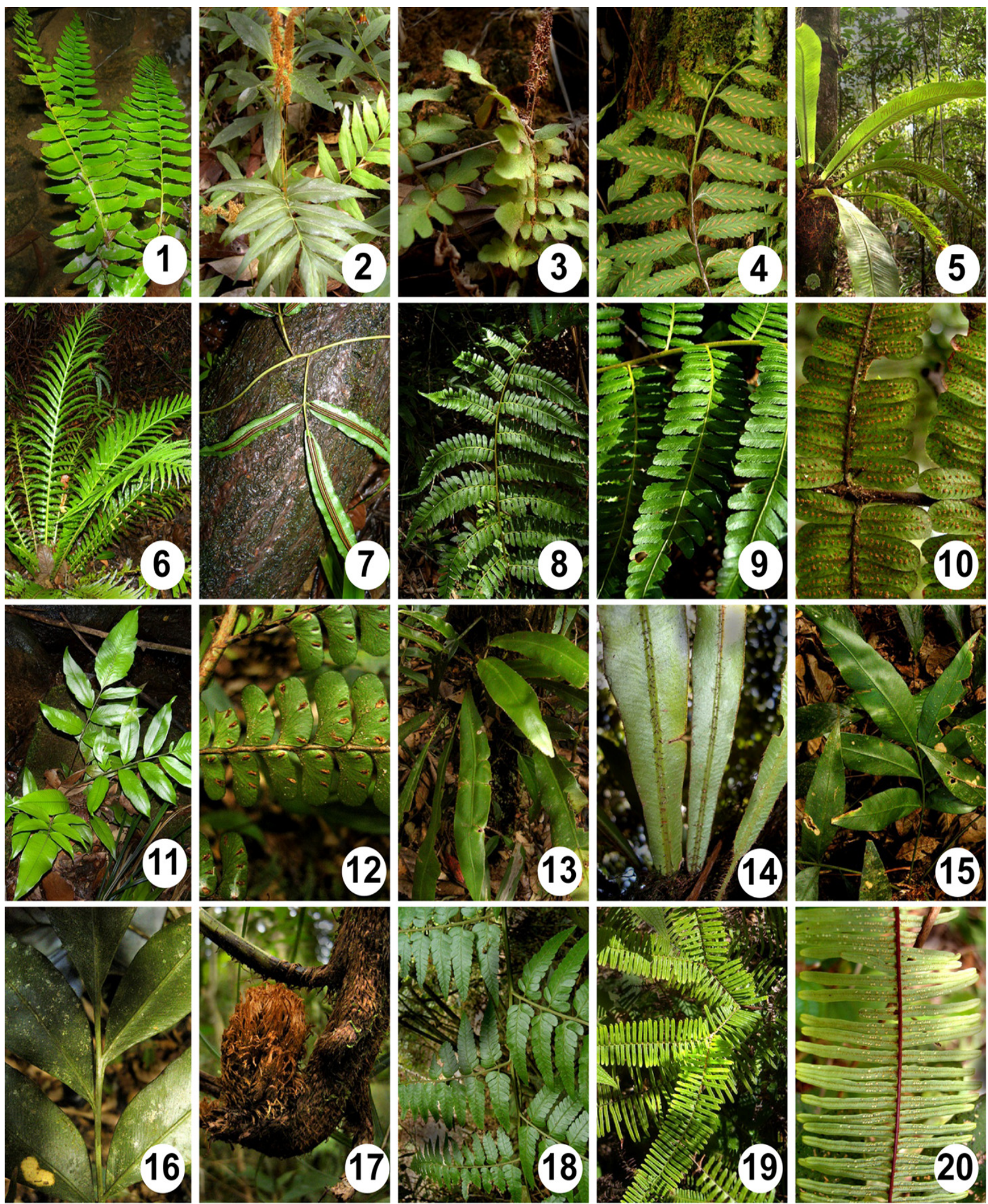

Figuras 1-20. Representantes de samambaias da Serra da Jiboia, Bahia, Brasil: 1- Anemia mandiocana: hábito; 2- Anemia phyllitidis: hábito; 3Anemia villosa: hábito; 4- Asplenium feei: face abaxial da fronde; 5- Asplenium serratum: hábito; 6- Blechnum brasiliense: hábito; 7- Salpichlaena volubilis: face abaxial da pina; 8-9- Cyathea abreviata: fronde e pinas; 10-Ctenitis distans: face abaxial das pínulas; 11- Cyclodium meniscioides: hábito; 12- Didymochlaena truncatula: face abaxial das pínulas; 13-14- Elaphoglossum insigne: hábito e face abaxial da lâmina; 15-16- Olfersia cervina: hábito e face adaxial das pinas; 17-18- Polybotrya speciosa: detalhe do caule densamente escamoso e parte da fronde; 19-20- Sticherus bifidus: parte da fronde e face abaxial da pina. 
2. Pinas acessórias presentes na base da pseudodicotomia das frondes; esporos triletes....Dicranopteris flexuosa

2'. Pinas acessórias ausentes na base da pseudodicotomia das frondes; esporos monoletes

Gleichenella pectinata

7.1. Dicranopteris flexuosa (Schrad.) Underw., Bull. Torrey Bot. Club 34: 254. 1907.

Terrestre, formando densas populações juntamente com Gleichenella pectinata, que recobrem grande parte dos barrancos na borda da mata, em local bastante ensolarado, a ca. 510 m s.n.m. Foi observada também associada a indivíduos de Sticherus bifidus; neste caso, forma populações menores, em altitudes maiores (ca. 720 m s.n.m.). Caracteriza-se por apresentar pinas 1- ou 2-furcadas com um par de pinas acessórias na base, ramos da bifurcação de tamanhos semelhantes, esporos triletes. Assemelha-se a Gleichenella pectinata, podendo ser diferenciada pelas características apresentadas na chave.

Distribuição. Neotropical, do sudeste dos Estados Unidos ao Paraguai e Brasil (AM, MT, MS, GO, DF, CE, PE, AL, BA, MG, RJ, SP, PR, SC e RS).

7.2. Gleichenella pectinata (Willd.) Ching, Sunyatsenia 5: 276. 1940.

Terrestre, encontrada em barrancos na borda da mata, em local bastante ensolarado, a ca. $510 \mathrm{~m}$ s.n.m. Caracteriza-se por apresentar pinas 2-4-furcadas, sem pinas acessórias na base, ramos da bifurcação de tamanhos desiguais, esporos monoletes. É a única espécie do gênero. É pioneira e a mais invasiva da família (Østergaard-Andersen \& Øllgaard 2001).

Distribuição. Do México ao Brasil (AC, AM, PA, CE, PE, AL, BA, MT, MS, GO, DF, MG, RJ, SP, PR e SC).

\subsection{Sticherus bifidus (Willd.) Ching, Sunyatsenia 5: 282.}

1940. 21

Figuras 19 e 20.

Terrestre, ocorrendo em local ensolarado, a ca. $720 \mathrm{~m}$ s.n.m. Caracteriza-se pela lâmina até 3-furcada, segmentos cobertos por escamas aracnoides e fibrilosas, castanho-clara na face abaxial.

Distribuição. Sul do México, América Central, Antilhas, Venezuela, Colômbia, Trinidad, Guiana, Equador, Peru, Bolívia, Paraguai e Brasil (MT, GO, CE, BA, MG, RJ, SP, $\mathrm{PR}, \mathrm{SC}$ e RS).

\section{Hymenophyllaceae}

1. Indúsio bivalvar.

2. Lâmina com tricomas nas nervuras e margens. Hymenophyllum hirsutum

2'. Lâmina glabra.

3. Lâmina 1-pinada a 1-pinado-pinatífida; estípite não alado Hymenophyllum asplenioides
3'. Lâmina 2-4-pinatífida; estípite alado.

1'. Indúsio tubular. Hymenophyllum polyanthos

4. Lâmina com falsas nervuras paralelas à margem; tricomas estrelados no enseio e margem

Didymoglossum krausii

4'. Lâmina sem falsas nervuras paralelas à margem, glabra ou com tricomas simples ou estrelados, neste caso também dispostos sobre as nervuras.

5. Rizoma longo-reptante com raízes escassas e finas.

6. Estípite alado quase até sua base; raque ampla mente alada; ala quase tão larga quanto à raque....

Polyphlebium diaphanum

6'. Estípite não alado ou alado apenas próximo ao ápice; raque estreitamente alada; ala mais estreita do que a raque..Polyphlebium hymenophylloides

5'. Rizoma ereto, ascendente ou longo-reptante, neste caso com raízes numerosas e robustas.

7. Tecido laminar com mais de uma camada de células de espessura. Trichomanes elegans

7'. Tecido laminar apenas com camada de células de espessura.

8. Lâmina glabra........ Trichomanes arbuscula

8'. Lâmina indumentada.

9. Tricomas simples; rizoma ascendente......

Trichomanes pilosum

9'. Tricomas estrelados; rizoma longo-reptante. Trichomanes polypodioides

8.1.Didymoglossum krausii (Hook. \& Grev.) C.Pres1, Hymenophyllaceae 115. 1843.

Figuras 21 e 22.

Epífita, no interior da mata, a 770-800 m s.n.m. Caracteriza-se por apresentar falsas nervuras parcialmente paralelas à margem da lâmina, tricomas estrelados no enseio entre os segmentos e, na margem, tricomas simples ou bífidos.

Distribuição. Dos Estados Unidos ao Paraguai, Argentina e Brasil (PA, MT, CE, PE, AL, BA, MG, ES, RJ, SP, PR e SC).

8.2. Hymenophyllum asplenioides ( $\mathrm{Sw}$.) Sw., J. Bot. (Schrader) 1800(2): 98. 1801.

Figura 23.

Epífita, no interior da mata, a ca. 770 m s.n.m. Caracteriza-se pela lâmina 1-pinada a 1-pinado-pinatífida, glabra, e raque amplamente alada.

Distribuição. México, América Central, Cuba, Jamaica, Porto Rico, Trinidad, Guiana, Venezuela, Colômbia e Brasil (BA, MG, RJ, SP, PR, SC e RS).

8.3. Hymenophyllum hirsutum (L.) Sw., J. Bot. (Schrader) 1800(2): 99. 1801.

Figura 24.

Epífita, no interior da mata, a ca. 730 m s.n.m. Caracteriza-se pela presença de tricomas em ambas as superfícies 
das nervuras e nas margens, pecíolo delicado, alado geralmente até o meio e próximo à base.

Distribuição. México, América Central, Antilhas, Guiana, Guiana Francesa, Suriname, Venezuela, Colômbia, Equador, Peru, Bolívia e Brasil (PA, CE, PE, BA, MG, RJ, SP, PR, SC e RS).

8.4. Hymenophyllum polyanthos (Sw.) Sw., J. Bot. (Schrader) 1800(2): 102. 1801.

Epífita, no interior da mata, a ca. 630 m s.n.m. Caracteriza-se pela lâmina glabra, 2-pinatífida a 4-pinatífida, segmentos com margem plana e invólucro oval. É bastante polimorfa, com caracteres que parecem variar nas diferentes regiões geográficas (Nonato 2004).

Distribuição. Pantropical. No Brasil: RR, AP, AM, PA, MT, GO, CE, PE, BA, MG, RJ, SP, PR, SC e RS.

\subsection{Polyphlebium diaphanum (Kunth) Ebihara \& Dubuis-} son, Blumea 51(2): 20. 2006.

Epífita, no interior da mata, a ca. 720 m s.n.m. Caracteriza-se pela lâmina 2- ou 3-pinatífida, pecíolo alado quase até sua base, raque amplamente alada, cada ala quase tão larga quanto à raque. Assemelha-se a Polyphlebium hymenophylloides e Tryon \& Stolze (1989a) consideramnas indistinguíveis, sendo as características utilizadas para separá-las variáveis e não relacionadas. Trabalhos mais recentes (Pacheco 1995; Mickel \& Smith 2004), no entanto, reconhecem ambas as espécies, apontando as características distintivas entre elas (apresentadas na chave).

Distribuição. Sul do México, América Central, Antilhas, Trinidad, Guiana, Guiana Francesa, Venezuela, Colômbia, Equador, Peru, Bolívia e Brasil (BA, MG, SP, PR).

8.6. Polyphlebium hymenophylloides (Bosch) Ebihara \&

Dubuisson, Blumea 51(2): 20. 2006.

Epífita em tronco caído no interior da mata, a ca. $770 \mathrm{~m}$ s.n.m. Caracteriza-se pela lâmina 2- ou 3-pinatífida, pecíolo não alado ou alado apenas próximo ao ápice, raque estreitamente alada, cada ala mais estreita do que a raque. Assemelha-se a Polyphlebium diaphanum (ver comentários desta espécie).

Distribuição. Sul do México, América Central, Antilhas, Trinidad, Venezuela, Colômbia, Guiana, Guiana Francesa, Suriname, Equador e Brasil (BA, SP e PR).

\subsection{Trichomanes arbuscula Desv., Mém. Soc. Linn. Paris} 6: 326.1827.

Figura 25.

Epífita, no interior da mata, a ca. 760 m s.n.m. Caracteriza-se pelas frondes monomorfas a levemente dimorfas e estípite nitidamente alado até a base. Segundo Zuquim et al. (2008), Trichomanes bicorne Hook., espécie da Bacia Amazônica, pode ser confundida com $T$. arbuscula, porém esta última difere por apresentar frondes menores, ca. $5 \mathrm{~cm}$ compr., e em menor número por indivíduo (vs. pinas maiores, ca. $10 \mathrm{~cm}$ compr., e em maior número em T. bicorne).

Distribuição. Jamaica, Trinidad, Guiana, Guiana Fran- cesa, Suriname, Venezuela, Colômbia, Peru e Brasil (AP, PA, MT, PE, BA e ES).

\subsection{Trichomanes elegans Rich., Actes Soc. Hist. Nat. Paris}

1: 114.1792.

Epífita, no interior da mata, a ca. 690 m s.n.m. Caracteriza-se pelas pinas fortemente denteadas, soros geralmente arqueados e tecido com mais de uma camada de células de espessura. Segundo Tryon \& Stolze (1989a), uma das espécies mais semelhantes a ela é Trichomanes rigidum $\mathrm{Sw}$., com a qual pode crescer associada. No entanto, esta última pode ser distinguida por possuir o tecido laminar com apenas uma célula de espessura, como todas as demais espécies do gênero (vs. lâmina com mais de uma célula de espessura em $T$. elegans).

Distribuição. Da Nicarágua ao Brasil (RR, AP, AM, PA, AC, MT, BA, MG, ES, RJ, SP, PR e SC).

8.9. Trichomanes pilosum Raddi, Opusc. Sci. 3: 296.1819.

Epífita em tronco caído, a ca. 720 m s.n.m. Caracterizase pelo caule reptante a ascendente, lâmina pinatífida, com indumento formado por tricomas simples, castanhos, e indúsio subtendido pelas nervuras laterais. Segundo Nonato (2004), assemelha-se a T. crispum L. e T. cristatum Kaulf. A primeira difere por apresentar o caule ereto e o indúsio não subtendido pelas nervuras laterais. Trichomanes cristatum difere por possuir as frondes eretas, lâmina linear a linearlanceolada (vs. frondes arqueadas, lâmina lanceolada a deltoide em T. pilosum).

Distribuição. Bolívia, Paraguai, Argentina, Uruguai e Brasil (MT, MS, GO, DF, PE, BA, MG, ES, RJ, SP, PR, SC e RS).

8.10. Trichomanes polypodioides L., Sp. Pl. 2: 1098. 1753. Figura 26.

Epífita, no interior da mata, a 730-790 m s.n.m. Caracteriza-se pela lâmina pinatífida com tricomas estrelados sobre as nervuras e margens. Segundo Tryon \& Stolze (1989a), espécimes menores de Trichomanes polypodioides podem ser confundidos com T. reptans Sw. [Didymoglossum reptans (Sw.) C.Presl] ou outras espécies do gênero que se assemelham na delicadeza, rizoma longo-reptante, pequeno, lâmina pinatífida, tricomas marginais estrelados e aspecto geral. Contudo, estas podem ser facilmente distinguidas, pois as espécies consideradas no gênero Didymoglossum Desv. apresentam falsas nervuras paralelas às verdadeiras, característica que não ocorre no gênero Trichomanes L. (Ebihara et al. 2006).

Distribuição. Do México à Argentina, Uruguai e Brasil (AP, MT, GO, PE, BA, MG, ES, RJ, SP, PR, SC e RS).

\section{LiNDSAEACEAE}

1. Estípite cilíndrico; lâmina subcoriácea ..Lindsaea stricta

1 '. Estípite anguloso; lâmina cartácea.

2. Estípite castanho-escuro na base e estramíneo 
distalmente; pínulas semilunares

Lindsaea lancea

2'. Estípite castanho-escuro a castanho-avermelhado em toda a sua extensão; pínulas trapeziformes.

Lindsaea quadrangularis

9.1. Lindsaea lancea (L.) Bedd., Suppl. Ferns Brit. Ind.: 6. 1876.

Terrestre ou rupícola, ocorrendo na borda ou interior da mata, a ca. 620 m s.n.m. Caracteriza-se pela lâmina 1- ou 2pinada, pínulas semilunares, com margem crenulada.

Distribuição. Do México ao Paraguai e Brasil (AM, PA, AC, RO, MT, GO, PI, CE, PE, AL, BA, MG, ES, RJ, SP, $\mathrm{PR}, \mathrm{SC}$ e RS).

9.2. Lindsaea quadrangularis Raddi, Opusc. Sci. Bol. 3: 294. 1819.

Terrestre, no interior da mata, a ca. 720 m s.n.m. Caracteriza-se pela raque quadrangular, sulcada adaxialmente, lâmina 2-pinada, pínulas trapeziformes.

Distribuição. Paraguai e Brasil (BA, MG, RJ, SP, PR, SC e RS).

9.3. Lindsaea stricta (Sw.) Dryand., Trans. Linn. Soc. London 3: 42. 1797.

Terrestre ou rupícola, em barranco na borda da mata, a ca. 620 m s.n.m. Caracteriza-se pelo estípite cilíndrico, lâmina linear, 1-pinada, pinas reduzidas no ápice da fronde.

Distribuição. Do sul do México ao Brasil (RR, AP, AM, PA, AC, RO, MT, GO, DF, MA, PE, AL, BA, MG, ES, RJ, $\mathrm{SP}$ e SC).

\section{LOMARIOPSIDACEAE}

1. Frondes dimorfas; soros acrosticoides

Lomariopsis marginata

1'. Frondes monomorfas; soros arredondados.

2. Rizoma com escamas concolores

Nephrolepis cordifolia

2'. Rizoma com escamas bicolores.

3. Estípite e raque com escamas esparsas ou densas. Nephrolepis rivularis

3'. Estípite e raque glabros, exceto na base das pinas. Nephrolepis pendula

10.1. Lomariopsis marginata (Schrad.) Kuhn in Decken, Reis Ost-Afr. Bot. 3 (3): 22. 1879.

Figuras 27 e 28.

Hemiepífita no interior da mata, a 700-780 m s.n.m. Caracteriza-se pela combinação de escamas castanhoavermelhadas no rizoma, as quais apresentam um brilho esbranquiçado (principalmente em direção ao ápice), não observado em outras espécies que apresentam escamas avermelhadas no rizoma (Moran 2000). Segundo Moran (2000), assemelha-se a L. japurensis (Mart.) J.Sm. e estas não podem ser distinguidas se faltar no espécime o rizoma ou a lâmina completa, pois a melhor maneira de diferenciálas é pelas escamas do rizoma (mais estreitas e escuras em L. japurensis, nunca com o brilho esbranquiçado). A arquitetura da fronde de ambas as espécies é semelhante, mas $L$. japurensis tem menos pares de pinas (8-12 pares). Além disso, a lâmina de $L$. marginata é mais ampla na base e não reduzida a pequenas pinas elípticas, com menos de $1 / 3$ do tamanho das maiores pinas medianas, como ocorre nos espécimes de L. japurensis.

Distribuição. Endêmica do Brasil: BA, MG, ES, RJ, SP, PR e SC.

10.2. Nephrolepis cordifolia (L.) C.Presl, Suppl. Tent. Pterid.: 79. 1836.

Epífita, a ca. 770 m s.n.m. Caracteriza-se pelo rizoma com escamas concolores, lâmina glabra, pinas com base arredondada a cordada basioscopicamente, cordada acroscopicamente, pecíolo e raque com escamas esparsas ou densas, indúsio reniforme. Assemelha-se a Nephrolepis pectinata (Willd.) Schott e N. pendula. A primeira se distingue pelas escamas bicolores no rizoma, a base das pinas cuneada no lado basiscópico e truncada ou arredondada acroscopicamente. A segunda difere pelas características apresentadas na chave.

Distribuição. Pantropical, sendo introduzida na América Tropical. No Brasil: PE, BA, MG, RJ, PR e RS.

\subsection{Nephrolepis pendula (Raddi) J.Sm., J. Bot. (Hooker)} 4: 197.1841.

Epífita, no interior da mata, a ca. 660 m s.n.m. Caracteriza-se pelas frondes longas e pendentes, glabras, com pecíolos lustrosos, geralmente sem escamas, soros quase marginais e indúsio reniforme com sinus amplo (Hovenkamp \& Miyamoto 2005). É semelhante à Nephrolepis cordifolia, podendo ser distinguida pelas características na chave.

Distribuição. De Cuba ao Brasil (RR, AC, GO, BA, MG, ES, RJ, SP, PR e SC).

10.4. Nephrolepis rivularis (Vahl) Mett. ex Krug in Urban, Bot. Jahrb. Syst. 24: 122. 1897.

Figuras 29 e 30.

Epífita no interior da mata, a ca. 730 m s.n.m. Caracteriza-se pelas escamas do rizoma bicolores, com porção central mais escura, raque frequentemente com aspecto crispado causado pelas escamas persistentes e ciliadas nas margens, pinas com base desigual, glabras adaxialmente e com escamas esparsas na face abaxial (Hovenkamp \& Miyamoto 2005).

Distribuição. De Cuba e Sul do México ao sul da Bolívia, leste das Pequenas Antilhas e Brasil (RR, AP, AM, PA, AC, RO, PE, BA, ES, RJ, SP, PR e SC).

\section{LYCOPODIACEAE}

1. Ramos de diâmetros diferentes; esporofilos decíduos, reu nidos em estróbilos pendentes.........Lycopodiella cernua 1'. Ramos de diâmetros iguais; esporofilos perenes, não reu 
nidos em estróbilos.

2. Planta pendente; microfilos aciculares; esporângios formados na porção medial e distal dos ramos.

Phlegmariurus acerosus

2'. Planta ereta; microfilos linear-acuminados; esporângios formados na porção distal dos ramos

Phlegmariurus pungentifolius

\subsection{Lycopodiella cernua (L.) Pic. Serm., Webbia 23: 165.} 1968.

Terrestre, na borda da mata, em local ensolarado, a ca. 780 m s.n.m. Caracteriza-se pelo caule prostrado com ramos laterais eretos, ramificados, encerrando estróbilos sésseis e pendentes.

Distribuição. Pantropical. No Brasil: AM, MG, MS, MA, PE, BA, MG, RJ, SP e PR.

11.2. Phlegmariurus acerosus (Sw.) B.Øllg. Rodriguésia 63(2): 480. 2012.

Figura 31.

Epífita, no interior da mata, a ca. 650 m s.n.m. Caracteriza-se pelos ramos pendentes, com microfilos aciculares e esporofilos distribuídos na porção distal e medial dos ramos.

Distribuição. Norte da América Tropical e Brasil (BA, MG, RJ, SP, PR, SC e RS).

11.3. Phlegmariurus pungentifolius (Silveira) B.Øllg.

Rodriguésia 63(2): 481. 2012.

Terrestre, a ca. 800 m s.n.m. Caracteriza-se pelos ramos eretos, caule não visível entre os microfilos, estes linearacuminados e esporofilos dispostos apenas na porção distal dos ramos. Pode ser confundida com Huperzia nuda (Nessel) B.Øllg. \& P.G.Windisch, espécie restrita à Região Sudeste, porém esta possui caule menos ramificado e visível entre os microfilos (Ramos \& Sylvestre 2010).

Distribuição. Endêmica do Brasil: BA, MG e RJ

\section{LygODIACEAE}

12.1. Lygodium volubile Sw., J.Bot. (Schrader) 1801(2): 304. 1803.

Terrestre, na borda da mata, a ca. 620 m s.n.m. Caracteriza-se pela fronde escandente, lâmina 2-pinada, pínula apical 1-furcada, as férteis apresentando margem modificada com projeções encerrando os esporângios. Difere de L. venustum Sw., que também ocorre no Brasil, por apresentar as pínulas mais ou menos do mesmo tamanho, não lobadas na base, (vs. pínulas de tamanho desigual, as proximais maiores, e lobadas na base em L. venustum).

Distribuição. Do Sul do México a Argentina e Brasil (PA, PE, AL, BA, MG, RJ, SP, PR, SC e RS)

\section{Marattiaceae}

13.1. Danaea geniculata Raddi, Opusc. Sci. Bol. 3: 281. 1819.
Figura 32.

Terrestre, no interior da mata, a ca. 780 m s.n.m. Caracteriza-se pelo rizoma ereto com muitas raízes adventícias, estípite com 1 a 3 nós, pinas com ápice acuminado, pina terminal conforme. Difere de Danaea leprieurii Kunze, espécie semelhante da Amazônia, principalmente por esta apresentar alas na raque. Essas duas espécies representam hoje o que se conhecia como D. elliptica Sm. Segundo Christenhusz \& Tuomisto (2006), D. elliptica é sinônimo taxonômico de D. nodosa (L.) Sm. (espécie que não apresenta nós no pecíolo). Devido a atual circunscrição, a distribuição da espécie permanece duvidosa.

Distribuição. Endêmica do Brasil: PE, BA, RJ e SP.

\section{Ophioglossaceae}

14.1. Ophioglossum palmatum L., Sp. Pl. 2: 1062. 1753.

Epífita em palmeiras, na borda da mata, a ca. $730 \mathrm{~m}$ s.n.m. O hábito epifítico, juntamente com a lâmina estéril pendente, palmatilobada, com os sinângios dispostos dorsalmente na base da lâmina caracterizam esta espécie.

Distribuição. Pantropical. No Brasil: AM, BA, RJ, SP, $\mathrm{SC}$ e RS.

\section{Polypodiaceae}

1. Frondes dimorfas.

2. Tecido laminar glabro.. Microgramma lycopodioides

2'. Tecido laminar com escamas.

3. Escamas alaranjadas; lâmina estéril oval, elíptica a oblonga. Microgramma reptans

3'. Escamas alvacentas; lâmina estéril cordiforme, oval ou oblonga....... Microgramma vacciniifolia

1'. Frondes monomorfas.

4. Lâmina inteira.

5. Lâmina com margem serrulada; soros formando cenossoros Cochlidium serrulatum

5'. Lâmina com margem inteira; soros não formando cenossoros.

6. Tecido laminar escamoso; soros em apenas uma fileira entre a costa e a margem da lâmina.

7. Escamas do rizoma circulares a elípticas; soros geralmente oblongos, mais longos que largos; estípite achatado.

Pleopeltis astrolepis

7'. Escamas do rizoma lanceoladas a ovais; soros arredondados, estípite cilíndrico.

Pleopeltis macrocarpa

6'. Tecido laminar sem escamas; soros em três ou mais fileiras entre a costa e a margem da lâmina. 8. Rizoma curto-reptante; nervuras laterais forman do um ângulo de $65-75^{\circ}$ com a costa; 7-12 aréolas entre a costa e a margem.....

Campyloneurum acrocarpon

8'. Rizoma longo-reptante; nervuras laterais for mando um ângulo de 50-60 com a costa; (4)5-7 aréolas entre a costa e a margem......... 

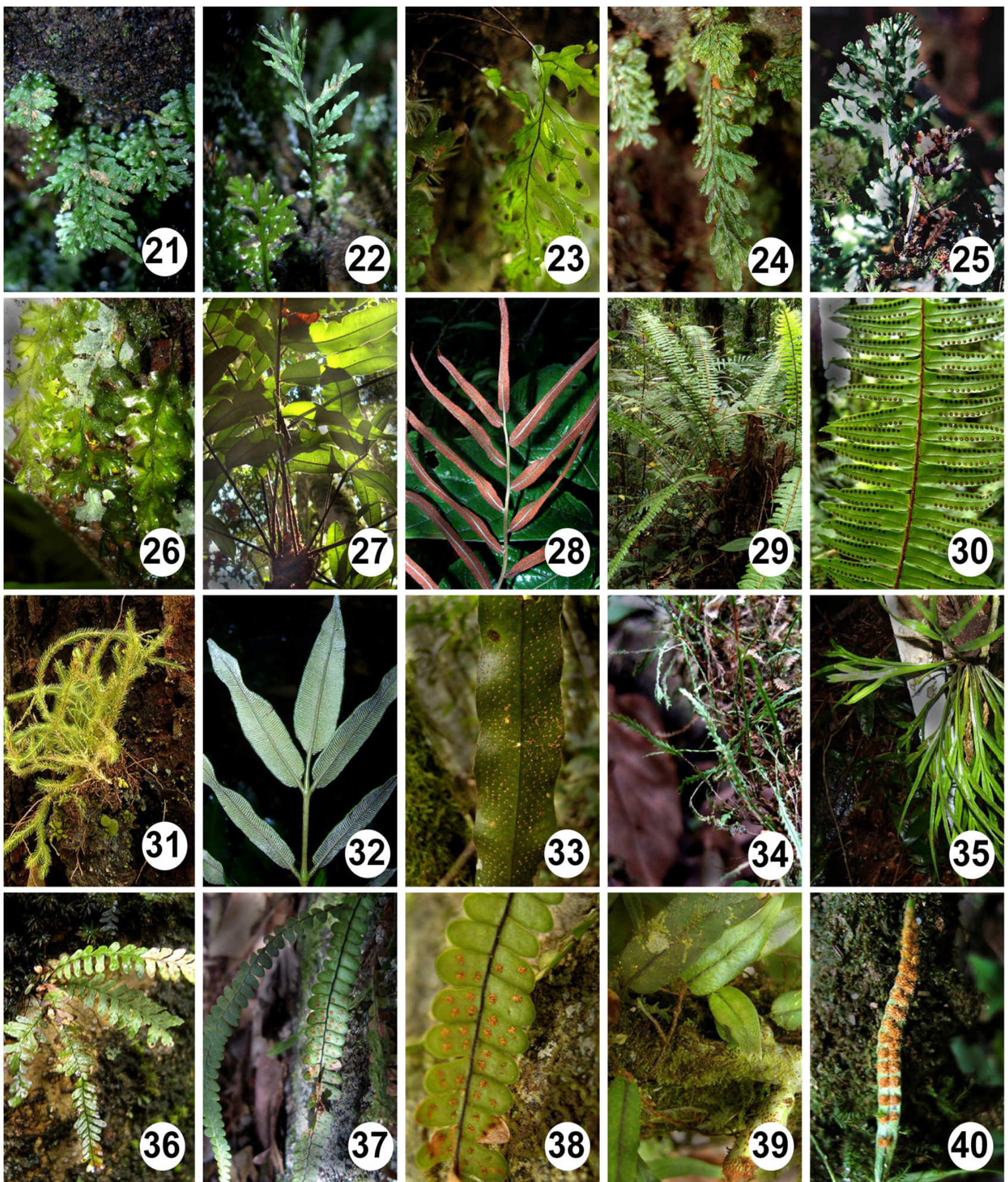

Figuras 21-40. Representantes de samambaias e licófitas da Serra da Jiboia, Bahia, Brasil: 21-22- Didymoglossum krausii: hábito e fronde; 23Hymenophyllum asplenioides: hábito; 24- Hymenophyllum hirsutum: hábito; 25- Trichomanes arbuscula: fronde; 26- Trichomanes polypodioides: hábito; 27-28- Lomariopsis marginata: parte da fronde estéril e fronde fértil; 29-30- Nephrolepis rivularis: hábito e face abaxial da fronde; 31Huperzia acerosa: hábito; 32- Danaea geniculata: face abaxial das pinas; 33- Campyloneurum nitidum: face abaxial da lâmina; 34- Cochlidium serrulatum: hábito; 35- Dicranoglossum furcatum: hábito; 36- Lellingeria suspensa: hábito; 37-38- Melpomene melanosticta: hábito e face abaxial da fronde; 39-40- Microgramma reptans: hábito e face abaxial da lâmina fértil. 
Campyloneurum nitidum

4'.Lâmina pinatissecta, 1-pinada ou subdicotomicamente furcada.

9. Lâmina subdicotomicamente furcada; soros lineares, marginais. ...... Dicranoglossum furcatum

9'. Lâmina pinatissecta ou 1-pinada; soros arredondados, abaxiais.

10. Rizoma com escamas não-clatradas.

11. Estípite sulcado adaxialmente; lâmina glabra; nervuras areoladas

.Phlebodium areolatum

11’. Estípite não sulcado, cilíndrico; lâmina pilosa; nervuras livres.

12. Rizoma longo-reptante; nervuras $1-$ 3(4)-furcadas; soros medianos

Pecluma pilosa

12'. Rizoma curto-reptante; nervuras simples; soros submarginais

Pecluma sicca

10'. Rizoma com escamas clatradas.

13. Rizoma reptante; frondes articuladas; esporos monoletes, aclorofilados

14. Rizoma com escamas negras; lâmina pinatissecta......

Serpocaulon catharinae

14'. Rizoma com escamas castanhas; lâmina 1-pinada.

Serpocaulon triseriale

13'. Rizoma ascendente a ereto; frondes não articuladas; esporos triletes, clorofilados.

15. Escamas do caule com margens setulosas; segmentos com ápice obtuso.

..Lellingeria suspensa

15 '. Escamas do caule sem margens setulosas, glabras; segmentos com ápice arre dondado......Melpomene melanosticta

15.1. Campyloneurum acrocarpon Fée, Cr. Vasc. Br. 1: 115; tab. 35, fig. 3. 1869.

Epífita, no interior da mata, a 750-800 m s.n.m. Caracteriza-se por apresentar o rizoma longo-reptante com escamas ovais, levemente buladas, lâmina lanceolada, cartácea, longamente decorrente na base (Léon 1992).

Distribuição. Endêmica do Brasil: BA, MG, SP, PR, SC e RS.

15.2. Campyloneurum nitidum (Kaulf.) C.Presl, Tent. Pterid.: 190. 1836. Figura 33.

Epífita, no interior da mata, a ca. 770 m s.n.m. Caracteriza-se por apresentar as escamas do rizoma com ápice obtuso e lâmina lanceolada, atenuada em ambas as extremidades (Léon 1992). Segundo Léon (1992), tem sido confundida com C. phyllitidis (L.) C.Presl. A primeira difere principalmente por possuir o rizoma mais estreito, 3-4 mm larg., com escamas de ápice obtuso e lâmina foliar com ápice ate- nuado [vs. rizoma relativamente mais largo, (4-)6-15 mm larg., com escamas de ápice acuminado e lâmina foliar com ápice predominantemente caudado ou acuminado em $C$. phyllitidis].

Distribuição. América do Sul. No Brasil: PA, BA, MG, RJ, SP, PR, SC e RS.

15.3.Cochlidium serrulatum (Sw.) L.E.Bishop, Amer. Fern J. 68: 80. 1978.

Figura 34.

Epífita ou rupícola, no interior da mata, a ca. $700 \mathrm{~m}$ s.n.m. Caracteriza-se pelas frondes distantes entre si, lâmina serrulada em toda sua extensão e soros formando cenossoros no ápice. Apresenta ampla distribuição e grande variação morfológica, especialmente em relação ao grau de divisão e tamanho da fronde (Labiak \& Prado 2003).

Distribuição. Pantropical. No Brasil: RO, AM, PA, MT, BA, MG, ES, RJ, SP, PR e SC.

15.4. Dicranoglossum furcatum (L.) J.Sm. in Seemann, Bot. Voy. Herald: 232. 1854.

Figura 35.

Epífita, no interior da mata, a ca. 620 m s.n.m. Caracteriza-se pela lâmina subdicotomicamente furcada, segmentos linear-lanceolados, os estéreis com nervuras livres, algumas aréolas afastadas da costa, lâmina com escamas mais ou menos ovais, soros lineares, marginais. Assemelha-se a Pleopeltis desvauxii (Klotzsch) Salino, que difere por apresentar os segmentos estéreis predominantemente com uma aréola costal alongada, lâmina com escamas menores (ca. $0,2 \mathrm{~mm}$ vs. $0,5 \mathrm{~mm}$ compr. em Dicranoglossum furcatum), predominantemente circulares a curto-cuspitadas.

Distribuição. América Central, Antilhas, Venezuela e Brasil (RO, AP, AM, PA, AC, AL, PE, BA, ES e SP).

\subsection{Lellingeria suspensa (L.) A.R.Sm. \& R.C.Moran,} Amer. Fern J. 81(3): 87. 1991.

Figura 36.

Epífita, no interior da mata, a ca. 630 m s.n.m. Caracteriza-se por apresentar a lâmina 1-pinada, pinas com a margem plana ou levemente crenulada, raque esclerificada em ambas as faces, soros superficiais ou localizados em sulcos inconspícuos. Assemelha-se a Lellingeria depressa (C.Chr.) A.R.Sm. \& R.C.Moran, a qual pode ser diferenciada por apresentar a raque recoberta pelo tecido laminar e a margem dos segmentos crenulada, além dos soros localizados em criptas, imersos no tecido laminar (Labiak \& Prado 2005a).

Distribuição. Costa Rica, Panamá, Jamaica, Trinidad, Guiana, Suriname, Venezuela, Colômbia, Equador e Brasil (AP, BA, ES e SP).

15.6. Melpomene melanosticta (Kunze) A.R.Sm. \& R.C.Moran, Novon 2(4): 430. 1992.

Figuras 37 e 38 .

Rupícola, no interior da mata, juntamente com indiví- 
duos de Cochlidium serrulatum, a ca. 700 m s.n.m. Caracteriza-se pelo caule ereto, curto, estípite curto até $2 \mathrm{~cm}$ compr., lâmina e raque glabras. Assemelha-se a Melpomene moniliformis (Lag. ex Sw.) A.R.Sm. \& R.C.Moran, a qual difere pelo caule horizontal, geralmente longo-reptante com frondes esparsas, distantes entre si até $1 \mathrm{~cm}$, e o pecíolo até $8 \mathrm{~cm}$ compr. (Labiak \& Prado 2005b).

Distribuição. Do Sul do México ao Brasil (RR, AM, BA, MG, ES, RJ, SP e PR).

\subsection{Microgramma lycopodioides (L.) Copel., Gen. Filic.:} 185. 1947.

Epífita, no interior da mata, a ca. 720 m s.n.m. Caracteriza-se pelo rizoma com escamas ferrugíneas, peltadas e frequentemente decíduas, e lâmina glabra. É similar a Microgramma baldwinii Brade (Tryon \& Stolze 1993), a qual pode ser considerada apenas uma variação decorrente de diferenças geográficas e altitudinais. Tais espécies são diagnosticadas pela lâmina com textura coriácea e margem fortemente revoluta, com nervuras pouco visíveis, e soros profundamente imersos no tecido laminar em $M$. baldwinii e lâmina com textura cartácea a subcoriácea e margem plana com nervuras distintas, mais ou menos proeminentes, soros não ou levemente imersos em $M$. lycopodioides (Tryon \& Stolze, 1993).

Distribuição. Do México ao Brasil (RR, AP, AM, PA, AC, RO, MT, GO, CE, PE, AL, BA, MG, RJ, SP, PR, SC e RS).

15. 8. Microgramma reptans (Cav.) A.R.Sm., Proc. Calif. Acad. Sci., ser. 4, 40(8): 230. 1975.

Figuras 39 e 40.

Epífita, no interior da mata, a ca. 690 m s.n.m. Caracteriza-se pela lâmina fértil linear com soros cobrindo todo o limbo entre a costa e a margem ou, comumente, ultrapassando a margem. Quando estéril pode ser confundida com Microgramma tecta (Kaulf.) Alston, mas nesta última, a lâmina estéril raramente ultrapassa $2 \mathrm{~cm}$ compr., a base é truncada ou subcordada e as escamas do rizoma são, em sua maioria, não adpressas (vs. lâmina estéril comumente maior que $2 \mathrm{~cm}$ compr., com base cuneada, e escamas do rizoma geralmente um pouco adpressas na metade proximal em $M$. reptans; Tryon \& Stolze 1993).

Distribuição. Do México ao Brasil (AP, AM, PA, AC, RO, PE e BA).

\subsection{Microgramma vacciniifolia (Langsd. \& Fisch.) Copel.,} Gen. Fil. (Copeland): 185. 1947.

Epífita, a ca. 690 m s.n.m. Caracteriza-se pelo rizoma com escamas ovais a oblongo-filiformes. Segundo Tryon \& Stolze (1993), as estruturas na lâmina que podem parecer tricomas alvacentos são escamas filiformes fixadas por uma base circular e peltada, sendo abruptamente reduzidas, formando um ápice tortuoso. Tais escamas são comumente encontradas na nervura mediana, entre os esporângios e, mais raramente, por toda a face abaxial da lâmina. As escamas presentes no tecido laminar são frequentemente estreladas, ramificadas desde a base com projeções alongadas, finas e tortuosas. Estas parecem ser facilmente removidas, pois em alguns espécimes maduros, são praticamente inexistentes.

Distribuição. Antilhas, Colômbia, Venezuela, Paraguai, Argentina e Brasil (MS, PE, BA, RJ, SP, PR, SC e RS).

\subsection{Pecluma pilosa (A.M.Evans) M.Kessler \& A.R.Sm., Candollea 60 (1): 281. 2005.}

Figuras 41 e 42.

Epífita, no interior da mata, a ca. 700 m s.n.m. Caracteriza-se pelo estípite $1-5 \mathrm{~cm}$ compr., segmentos perpendiculares a raque, arredondados a obtusos; tricomas da raque e costa 1,5-2 mm compr., lâmina mais densamente pilosa ao redor dos soros. Segundo Evans (1969), assemelha-se a Pecluma ptilodon (Kunze) M.G.Price, diferindo principalmente por apresentar segmentos arredondados, tricomas mais longos na raque e costa e pecíolo muito curto (vs. segmentos obtusos, tricomas ca. $0,75 \mathrm{~mm}$ compr. e pecíolo $12-17$ cm compr. em Pecluma ptilodon).

Distribuição. Trinidad, Guiana Francesa, Venezuela, Peru, Bolívia e Brasil (AM, CE, BA, MG e RJ).

\subsection{Pecluma sicca (Lindm.) M.G.Price, Amer. Fern J.} 73(3): 115. 1983.

Epífita, no interior da mata, a ca. 690 m s.n.m. Distingue-se pelo pequeno tamanho, rizoma com escamas ferrugíneas e brilhantes, nervuras livres, soros submarginais. Assemelha-se a Pecluma truncorum (Lindm.) M.G.Price (Evans 1969). Esta difere por possuir os segmentos mais largos, 2,5-4,5 mm (vs. 1-2 mm em $P$. sicca) e escamas escuras (vs. ferrugíneas e brilhantes).

Distribuição. América do Sul. No Brasil: BA (primeiro registro), RJ, SP, PR, SC e RS.

\subsection{Phlebodium areolatum (Humb.\& Bonpl. ex Willd.)} J.Sm., J. Bot. (Hooker) 4: 59. 1841.

Epífita, na borda na mata, em local sombreado, a ca. 780 m s.n.m. Caracteriza-se pela lâmina pinatissecta e apenas uma série de soros entre a costa e a margem. Difere de Phlebodium aureum (L.) J.Sm. e P. decumanum (Willd.) J.Sm., principalmente por possuir apenas uma série de soros entre a costa e a margem (vs. 2 ou 3 na primeira e 3-7 na segunda).

Distribuição. Dos Estados Unidos ao Paraguai, Argentina e Brasil (MT, MS, BA, MG, RJ, SP, PR e SC).

\subsection{Pleopeltis astrolepis (Liebm.) E.Fourn., Mex. Pl. 1:} 87. 1872.

Epífita, no interior da mata, a ca. 730 m s.n.m. Caracteriza-se pelas escamas do rizoma arredondadas, obscurecidas por tricomas, lâmina inteira, com soros alongados na porção distal da lâmina.

Distribuição. Dos Estados Unidos ao Brasil (PE, BA, MG, RJ, SP, MS, PR e SC). 
15.14. Pleopeltis macrocarpa (Bory ex Willd.) Kaulf., Berlin. Jahrb. Pharm. Verbundenen Wiss. 21: 41. 1820.

Epífita, no interior da mata, a ca. 730 m s.n.m. Caracteriza-se pelo caule com escamas lanceoladas a ovais, bicolores, não obscurecidas por tricomas, lâmina inteira, soros arredondados.

Distribuição. Pantropical. No Brasil: PE, AL, BA, MG, ES, RJ, SP, PR, SC e RS.

\subsection{Serpocaulon catharinae (Langsd. \& Fisch.) A.R.Sm.,} Taxon 55(4): 928. 2006.

Epífita, no interior da mata, a ca. 620 m s.n.m. Caracteriza-se pelo rizoma com escamas escuras e esparsas e lâmina pinatissecta.

Distribuição. América do Sul. Amplamente distribuída na Mata Atlântica, ocorrendo como epífita ou rupícola, do Nordeste ao Sul do Brasil (PE, BA, MG, ES, RJ, SP, PR, SC e RS), e também em países vizinhos, do nível do mar a 2.200 m s.n.m. (Labiak \& Prado 2008).

\subsection{Serpocaulon triseriale (Sw.) A.R.Sm., Taxon 55 (4): 929. 2006. 35}

Epífita ou terrestre, no interior da mata, a ca. $660 \mathrm{~m}$ s.n.m. Caracteriza-se pela lâmina subcoriácea a coriácea, 1pinada, pinas adnatas à raque no lado acroscópico, 1 ou 2(3) fileiras de soros entre a costa e a margem e nervuras proeminentes.

Distribuição. É uma das espécies mais amplamente distribuída e mais variáveis do gênero, ocorrendo em quase todos os países neotropicais, desde o México até a América do Sul (Labiak \& Prado 2008). No Brasil, ocorre em diferentes tipos de vegetação como epífitas, rupícolas ou terrestres, nos estados do AM, PA, AC, CE, PE, AL, BA, GO, MT, MG, ES, RJ, SP, PR, SC e RS.

\section{Psilotaceae}

16.1. Psilotum nudum (L.) P.Beauv., Prodr. Aethéogam. 106: 112. 1805.

Figura 43.

Epífita, na borda da mata, a ca. 620 m s.n.m. Caracteriza-se por apresentar o caule sem raízes, revestido por tricomas castanho-escuros, rígidos, eixos aéreos angulosos e pelos sinângios formados pela fusão de três esporângios, dispostos espiraladamente. Psilotum nudum e $P$. complanatum $\mathrm{Sw}$. são as únicas duas espécies do gênero com ocorrência nas regiões tropicais e somente a primeira ocorre no Brasil. Psilotum complanatum difere por apresentar os eixos aéreos achatados, sinângios dispostos em pares subopostos ou alternos (Stolze 1983).

Distribuição. Pantropical. No Brasil: MT, MS, BA, RJ, PR, SC e RS.

\section{Pteridaceae}

1. Plantas epífitas; lâmina inteira.
2. Soros em sulcos rasos, com ou sem aletas nas margens, paráfises com célula apical alargada, esporos em sua maioria triletes.

Vittaria graminifolia

2'. Soros em sulcos profundos, com aletas nas margens, paráfises com célula apical não ou levemente alargada, esporos monoletes.

Vittaria lineata

1'. Plantas terrestres ou rupícolas; lâmina pinatífida, 1-pinada ou mais vezes dividida.

3. Pseudoindúsio com nervuras.

4. Lâmina 1-pinada.

5. Pinas articuladas à raque; soros oblongos

Adiantum deflectens

5'. Pinas não articuladas à raque; soros lineares........

Adiantum lucidum

4'. Lâmina 2-5-pinada.

6. Lâmina 2-pinada; estípite e raque escamosos..... Adiantum tetraphyllum

6'. Lâmina 4- ou 5-pinada na base; estípite e raque com tricomas

Adiantum abscissum

3'. Pseudoindúsio sem nervuras.

7. Soros com paráfises.

8. Lâmina 1-pinada. Pteris vittata

8'. Lâmina 1-pinado-pinatífida.

9. Lâmina esparsamente pubescente; pinas proximais furcadas, margem inteira.

Pteris decurrens

9'. Lâmina glabra; pinas proximais furcadas a pinatífidas, margem denticulada.

Pteris denticulata

7'. Soros sem paráfises.

10. Frondes monomorfas, radiadas; nervuras livres; soros oblongos Adiantopsis radiata

10'. Frondes dimorfas, palmadas ou pedadas; nervuras areoladas; soros lineares.

11. Estípite achatado dorsalmente; lâmina sem hidatódios........... Doryopteris collina

11'. Estípite cilíndrico; lâmina com hidatódios Doryopteris pentagona

17.1. Adiantopsis radiata (L.) Fée, Mém. Foug. 5: 145. 1852.

Terrestre, no interior da mata, a ca. 720 m s.n.m. Caracteriza-se pela lâmina 2-pinada com pinas dispostas radialmente, glabras, indúsios suborbiculares a oblongos. Segundo Tryon \& Stolze (1989b), o arranjo radiado, geralmente com 5-7 pinas (raramente 3, 4 ou mais numerosas), distingue fortemente Adiantopsis radiata das demais espécies do gênero.

Distribuição. Do México ao Paraguai, Argentina e Brasil (MT, MS, GO, CE, PE, BA, MG, ES, RJ, SP, PR, SC e RS).

17.2. Adiantum abscissum Schrad., Gott. Gel. Anz. 87: 872. 1824.

Terrestre, no interior da mata, a ca. 620 m s.n.m. Carac- 
teriza-se pelo rizoma curto-reptante, pseudoindúsio glabro.

Distribuição. Bolívia e Brasil (MT, MS, GO, CE, PE, AL, BA, MG, ES, RJ, SP, PR e SC).

17. 3. Adiantum deflectens Mart., Icon. Pl. Crypt.: 94. 1834.

Terrestre, na borda da mata, a ca. 440 m s.n.m. Caracteriza-se por apresentar o rizoma ereto, raque prolífera.

Distribuição. América tropical (Winter et al. 2007), do México à América do Sul. No Brasil: RO, TO, MT, MS, GO, DF, MA, PI, CE, PB, PE, AL, BA, MG, ES, RJ e SP.

17.4. Adiantum lucidum (Cav.) Sw., Syn. Fil.: 1211806. Figura 44.

Terrestre, no interior da mata, a ca. 790 m s.n.m. Caracteriza-se pelas pinas com base assimétrica, nervuras livres a parcialmente areoladas. Pode ser confundida com Adiantum dolosum Kunze, porém esta apresenta pinas com base simétrica (vs. assimétrica em A. lucidum) e menos numerosas (3-5 pares vs. 8-14 pares; Zuquim et al. 2008).

Distribuição. América Central, Jamaica, Trinidad, Venezuela, Colômbia, Guiana, Guiana Francesa, Equador, Peru e Brasil (AP, AM, PA, AC, PE, BA, MG e ES).

17.5. Adiantum tetraphyllum Humb.\& Bonpl.ex Willd., Sp. Pl., ed. 4 [Willdenow] 5: 441. 1810.

Terrestre, no interior da mata, a ca. 790 m s.n.m. Caracteriza-se pelo rizoma curto-reptante, pínulas dimidiadas e falcadas.

Distribuição. Do sul do México ao Paraguai e Brasil (RR, AP, AM, PA, MT, MS, GO, DF, CE, PE, BA, MG, RJ, SP, PR e SC).

17.6. Doryopteris collina (Raddi) J.Sm., J. Bot. (Hooker) 4: 163. 1841.

Rupícola, na borda da mata, a ca. 730 m s.n.m. Caracteriza-se pelo pecíolo castanho-escuro, achatado dorsalmente, e pela ausência de hidatódios na superfície adaxial da lâmina.

Distribuição. Guiana, Bolívia, Paraguai e Brasil (MS, PE, BA, MG, RJ, SP, PR, SC).

17.7. Doryopteris pentagona Pic.Serm., Webbia 60(1): 231; fig. 42. 2005.

Terrestre, na borda da mata, a ca. 440 m s.n.m. Caracteriza-se pela lâmina com hidatódios, glabra, lâmina fértil 1ou 2-pinatífido-pinatisecta, com soros interrompidos nos sinus.

Distribuição. Guiana, Venezuela, Bolívia, Paraguai, Argentina, Uruguai e Brasil (MT, CE, PE, BA, RJ, SP, PR, $\mathrm{SC}$ e RS).

17.8. Pteris decurrens C.Presl, Del. Prag. 1: 183. 1822.

Figuras 45 e 46.

Terrestre, no interior da mata, a ca. 790 m s.n.m. Carac- teriza-se pela base da pina distal e apical decorrente na raque, nervuras areoladas com uma aréola grande e alongada e outra aréola pequena entre duas cóstulas adjacentes (Prado \& Windisch 2000). Similar a Pteris lechleri Mett. e P. biaurita L., diferindo da primeira pela lâmina esparsamente pubescente (vs. lâmina com indumento conspicuamente seríceo) e da segunda pela estrutura das aréolas descrita acima (vs. nervuras parcialmente areoladas com somente uma aréola alongada, unida à costa entre duas cóstulas adjacentes; Prado \& Windisch 2000).

Distribuição. Venezuela, Colômbia, Equador, Peru, Bolívia, Chile e Brasil (BA, MG, ES, RJ, SP, PR, SC e RS).

17.9. Pteris denticulata Sw., Prodr. [O.P. Swartz]: 129. 1788. Figuras 47 e 48.

Terrestre, no interior da mata, a ca. 770 m s.n.m. Caracteriza-se pela raque alada, pina proximal variando de furcada a pinatífida geralmente no lado basiscópico, pina medial inteira, lanceolada

Distribuição. Cuba, Hispaniola, Porto Rico, Guiana, Paraguai, Argentina e Brasil (PA, MT, MS, MA, CE, PE, BA, MG, ES, RJ, SP, PR, SC e RS).

\subsection{Pteris vittata L., Sp. Pl. 2: 1074. 1753.}

Rupícola, na borda da mata, ca. 800 m s.n.m. Caracteriza-se pela lâmina imparipinada, pinas linares, com base truncada, não articuladas à raque, nervuras livres (Prado \& Windisch 2000). Assemelha-se a $P$. longifolia L., da qual difere por possuir pinas articuladas à raque (Prado \& Windisch 2000).

Distribuição. Pantropical, introduzida no Neotrópico (Prado \& Windisch 2000). No Brasil: PA, DF, PE, BA, MG, ES, RJ, PR e SC.

17.11. Vittaria graminifolia Kaulf., Enum. Filic.: 192. 1824. Figura 49.

Epífita, no interior da mata, ca. 700 m s.n.m. Caracteriza-se pela lâmina linear, soros lineares em sulcos pouco profundos, com ou sem aletas nas margens, célula apical das paráfises alargada, esporos predominantemente triletes. Frequentemente confundida com V. lineata (L.) Sm., sendo separadas, principalmente, pela diferença na forma dos esporos (monoletes em V. lineata vs. triletes em Vittaria graminifolia; Nonato \& Windisch 2004). Alguns espécimes de $V$. graminifolia podem apresentar esporos monoletes e triletes, contudo estes últimos são produzidos em maior quantidade (Nonato \& Windisch 2004).

Distribuição. Do Sul dos Estados Unidos ao Uruguai e Brasil (AM, MT, PE, BA, MG, ES, RJ, SP, PR, SC e RS).

17.12. Vittaria lineata (L.) Sm., Mém. Acad. Roy. Sci. (Turin) 5: 421; tab. 9, fig. 5.1793.

Epífita, no interior da mata, a ca. 700 m s.n.m. Caracteriza-se por apresentar soros em sulcos profundos, com aletas em ambos os lados, célula apical das paráfises não ou leve- 

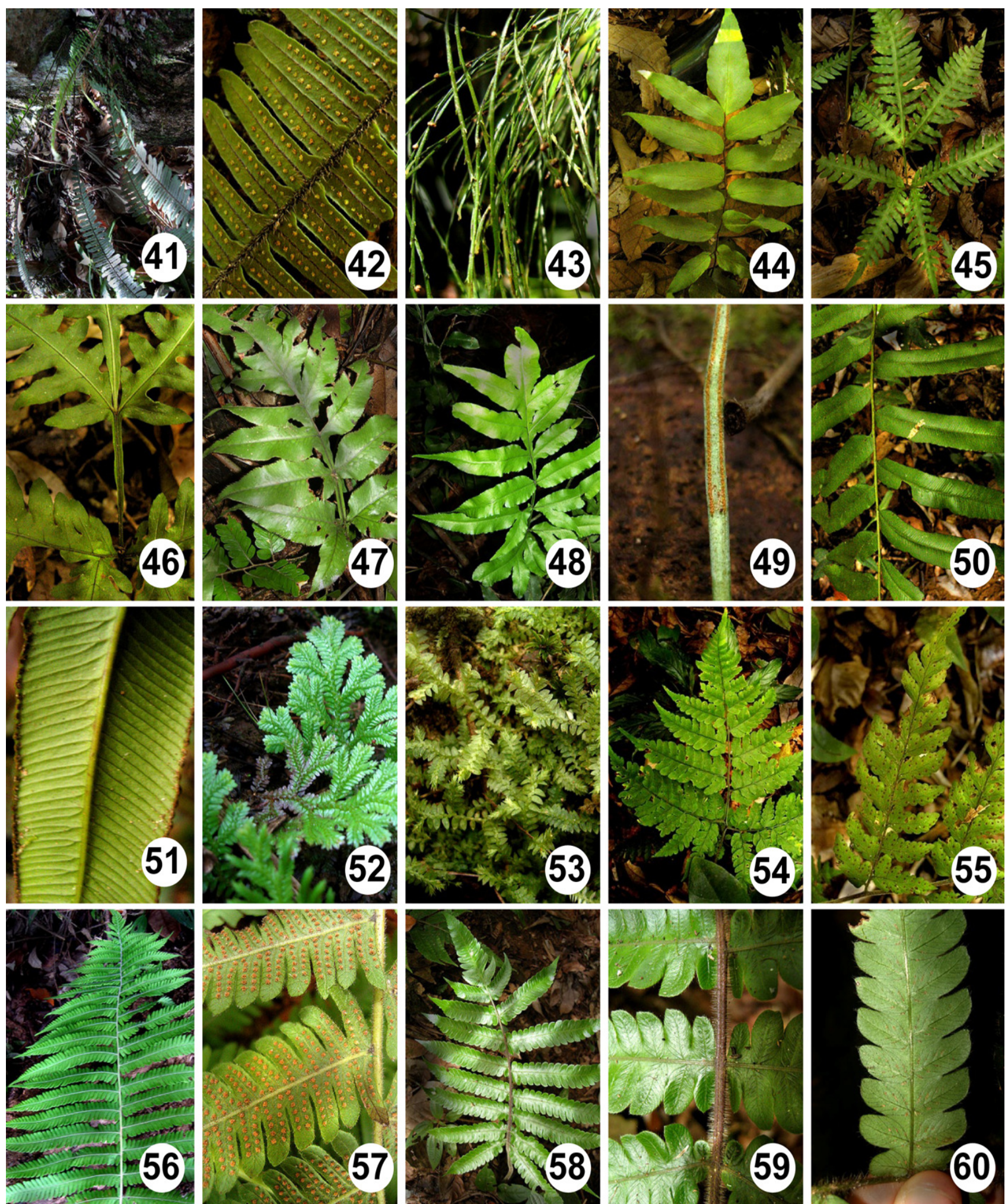

Figuras 41-60. Representantes de samambaias e licófitas da Serra da Jiboia, Bahia, Brasil: 41-42- Pecluma pilosa: hábito e face abaxial da fronde; 43Psilotum nudum: eixos aéreos e sinângios; 44- Adiantum lucidum: hábito; 45-46- Pteris decurrens: hábito e detalhe base da pina decorrente na raque; 47-48- Pteris denticulata: hábito; 49- Vittaria graminifolia: face abaxial da lâmina; 50-51- Saccoloma elegans: parte da fronde e face abaxial da pina. 52- Selaginella flexuosa: hábito; 53- Selaginella muscosa: hábito; 54-55- Triplophyllum hirsutum: hábito e face abaxial da pina; 56-57- Thelypteris hispidula: parte da fronde e face abaxil das pinas; 58-60- Thelypteris villosa: hábito, detalhe da raque pilosa e face abaxial da pina. 
mente alargada e esporos monoletes (Nonato \& Windisch 2004). Semelhante à Vittaria graminifolia (ver comentários na espécie precedente).

Distribuição. Do Sul dos Estados Unidos ao Paraguai, Uruguai e Brasil (AP, AM, PA, MT, MS, MA, CE, PE, BA, MG, ES, RJ, SP, PR, SC e RS).

\section{Saccolomataceae}

18.1. Saccoloma elegans Kaulf., Berlin. Jahrb. Pharm. Verbundenen Wiss. 21: 511820.

Figuras 50 e 51.

Terrestre, no interior da mata, a ca. 790 m s.n.m. Caracteriza-se pelo caule curto e compacto, lâmina 1-pinada, pina apical conforme, soros submarginais na terminação das nervuras. Difere de Saccoloma inaequale (Kunze) Mett., outra espécie com ocorrência na Bahia, por esta apresentar a fronde de 2-4-pinado-pinatífida.

Distribuição. Do Sul do México ao Brasil (RR, AM, PA, AC, RO, PE, AL, BA, MG, ES, RJ, SP, PR e SC).

\section{SchizaEaceae}

19.1. Schizaea elegans (Vahl) Sw., J. Bot. (Schrader) 1800(2): 1031801.

Terrestre, no interior da mata, a ca. 720 m s.n.m. Caracteriza-se pela lâmina flabelada, dicotomicamente lobada, glabra, com segmentos férteis na terminação das nervuras, pinatífidos, lanosos.

Distribuição. Dos Estados Unidos ao Brasil (AM, PE, BA, MG, PR e SC).

\section{Selaginellaceae}

1. Microfilos com face adaxial rugosa; estróbilos quadrangulares; esporofilos dorsais e ventrais de tamanhos e formas semelhantes. Selaginella flexuosa

1'. Microfilos com face adaxial lisa; estróbilos planos; esporofilos dorsais maiores e planos, os ventrais menores e abaulados.

Selaginella muscosa

20.1. Selaginella flexuosa Spring, Flora 21: 197. 1838.

Figura 52.

Terrestre no interior da mata, na margem de córrego ou associada a outros locais úmidos, a ca. $700 \mathrm{~m}$ s.n.m. Caracteriza-se pelo caule prostrado a subereto, microfilos laterais e axilares oblongos, margens denticuladas e face adaxial com aspecto rugoso.

Distribuição. México, América Central, Colômbia, Equador, Peru, Bolívia e Brasil (MG, PE, BA, MG, ES, RJ, SP, PR e SC).

20.2. Selaginella muscosa Spring, Fl. Bras. 1(2): 120. 1840. Figura 53.

Terrestre ou rupícola, no interior da mata, a ca. $700 \mathrm{~m}$ s.n.m. Caracteriza-se por apresentar os microfilos laterais assimétricos com base acroscópica arredondada, margens serreadas, face dorsal dos microfilos com cloroplastos conspicuamente visíveis (Hirai \& Prado 2000).
Distribuição. Trinidad e Tobago, Guiana, Venezuela, Colômbia, Peru, Paraguai, Argentina, Uruguai e Brasil (AM, CE, PE, AL, BA, MG, ES, RJ, SP, PR, SC e RS).

\section{Tectariaceae}

21.1. Triplophyllum hirsutum (Holttum) J.Prado \& R.C.Moran, Brittonia 61 (2): 121. 2008.

Figuras 54 e 55.

Terrestre, no interior da mata, a ca. 780 m s.n.m. Caracteriza-se pela raque puberulenta em ambas as faces, tricomas curtos, com 2-4 células e $0,1-0,3 \mathrm{~mm}$ compr., tecido glabro a puberulento entre as nervuras, nunca com tricomas glandulares e indúsio pubescente (Prado \& Moran 2008). Assemelha-se a Triplophyllum funestum (Kunze) Holttum, T. dicksonioides (Fée) Holltum e T. boliviense J.Prado \& R.C.Moran, que também ocorrem no Brasil, diferindo pela raque glabra ou esparsamente puberulenta adaxialmente na primeira e pela presença de tricomas glandulares abundantes em diversas partes nas duas últimas espécies (Prado \& Moran 2008).

Distribuição. América Central, Trinidad \& Tobago, Guiana, Guiana Francesa, Suriname, Venezuela, Colômbia, Peru e Brasil (RR, AP, AM, PA, RO, PE, BA e ES).

\section{Thelypteridaceae}

1. Indumento de tricomas pluricelulares; soros lineares a oblongos; indúsio ausente. Thelypteris villosa

1 '. Indumento de tricomas unicelulares; soros arredondados; indúsio presente.

2. Face adaxial das pinas pubescente com aspecto estrigoso; nervuras basais de segmentos adjacentes unindo-se ao enseio ou a uma curta nervura excurrente (até $5 \mathrm{~mm}$ compr.).

Thelypteris conspersa

2'. Face adaxial das pinas levemente pubescente, não estrigosa; nervuras basais de segmentos adjacentes sem pre unindo-se antes a uma longa nervura excurrente que se dirige ao enseio (maior que $5 \mathrm{~mm}$ compr.)

Thelypteris hispidula

\subsection{Thelypteris conspersa (Schrad.) A.R.Sm., Univ. Calif.} Publ. Bot. 59: 60. 1971.

Terrestre, próxima a córrego, a ca. 720 m s.n.m. Caracteriza-se pelo indumento denso da raque, face abaxial da costa e indúsio, com tricomas setiformes e glandulares, indumento da face adaxial dos segmentos entre as nervuras com aspecto estrigoso e indúsio com tricomas setiformes e glandulares. É semelhante a T. dentata (Forssk.) E.St.John. e T. hispidula (Decne.) C.F.Reed, diferindo pelas características citadas acima, enquanto nas últimas duas espécies o indumento da face adaxial dos segmentos não é estrigoso e o indúsio possui apenas tricomas setiformes. Além disso, em $T$. conspersa, as nervuras basais de segmentos adjacentes geralmente se unem ao enseio ou antes a uma curta nervura excurrente de ca. $5 \mathrm{~mm}$ compr. (vs. nervuras basais de segmentos adjacentes sempre se unindo antes a uma longa nervura excurrente que se dirige ao enseio em $T$. dentata e $T$. 
hispidula; Salino \& Semir 2002).

Distribuição. Hispaniola (Caribe), Panamá, Venezuela, Colômbia, Peru, Bolívia, Argentina, Paraguai, Uruguai e Brasil (BA, GO, MT, MS, MG, RJ, SP, PR, SC e RS).

22.2. Thelypteris hispidula (Decne.) C.F.Reed, Phytologia 17(4): 2831968.

Figuras 56 e 57.

Terrestre, na borda ou em clareira no interior da mata, exposta ao sol, a ca. 720 m s.n.m. Caracteriza-se principalmente pelos tricomas da face abaxial da costa de tamanhos variados, 3-5 mm compr. Assemelha-se a Thelypteris dentata (Forssk.) E.St.John., porém esta difere por apresentar os tricomas da face abaxial da costa de tamanho uniforme e atingindo no máximo 2 mm compr. (Salino \& Semir 2002).

Distribuição. Pantropical. No Brasil: AP, AM, PA, MT, GO, MA, PE, BA, MG, ES, RJ, SP, PR, SC e RS.

\subsection{Thelypteris villosa (Link) C.F.Reed, Phytologia 17:323. 1968.}

Figuras 58-60.

Terrestre, no interior da mata, a ca. 780 m s.n.m. Caracteriza-se pela presença de um indumento viloso no estípite, raque e face abaxial da costa com tricomas longos e pluricelulares, às vezes a face abaxial da costa pode apresentar-se com tricomas unicelulares, sempre maiores que 0,4 mm compr. (Salino \& Semir 2003). Essas características diferem-na de outra espécie fortemente relacionada, Thelypteris polypodioides (Raddi) C.F.Reed, a qual possui a lâmina glabra ou esparsamente pubescente, com tricomas unicelulares e curtos (Salino \& Semir 2003).

Distribuição. É considerada uma espécie rara, referida apenas para os estados do Rio de Janeiro e Bahia (Salino \& Semir 2003; Macedo et al. 2011).

\section{Agradecimentos}

O primeiro autor agradece aos seus familiares pela ajuda durante o trabalho de campo e ao CNPq pela bolsa de Mestrado. Agradecemos, pela confirmação das identificações, ao Dr Alan Smith (Dicranoglossum furcatum) e Dr Alexandre Salino (Thelypteris villosa), ao Dr. Paulo Günter Windisch, pela colaboração em Lycopodiaceae, ao PPGBotUEFS e HUEFS, incluindo seus funcionários, pela logística e infraestrutura. Agradecemos também aos revisores do manuscrito pelas valiosas sugestões.

\section{REFEREÊNCIAS}

Assis, E.L.M. 2007. Pteridófitas da Borda Oeste do Pantana SulMatogrossense, Brasil. Dissertação de Mestrado. Universidade Federal do Paraná.

Barros, I.C.L. 1998. Pteridófitas. In: M.L.S. Guedes \& M.D. Orge (eds), Checklist das Espécies Vasculares do Morro do Pai Inácio (Palmeiras) e Serra da Chapadinha (Lençóis) Chapada Diamantina. Bahia - Brasil. Universidade Federal da Bahia, Salvador, p. 12, 35-36.

Barros, I.C.L. \& Araújo, S.S. 2000. Flora Pteridofítica do Rio Mosquito Município de Lençóis, Chapada Diamantina Bahia, Brasil. Notas Preliminares. Boletim da Sociedade Broteriana 1: 145-162.

Carvalho-Sobrinho, J.G. \& Queiroz, L.P. 2005. Composição florística de um fragmento de Mata Atlântica na Serra da Jibóia, Santa Terezinha, Bahia, Brasil. Sitientibus série Ciências Biológicas 5: 20-28.

Casarino, J.E.; Mynssen, C.M. \& Messias, M.C.T.B. 2009. Schizaeales no Parque Estadual do Itacolomi, Minas Gerais, Brasil. Revista Brasileira de Botânica 32: 737-748.

Christenhusz, M.J.M. \& Tuomisto, H. 2006. Five new species of Danaea (Marattiaceae) from Peru and new status for $D$. elliptica. Kew Bulletin 61: 17-30.

Christensen, C. 1913. A monograph of the genus Dryopteris. Part I: the tropical American pinnatifid bipinnatifid species. Kongelige Danske Videnskabernes Selskab 10: 55-282.

Conservação Internacional do Brasil; Fundação SOS Mata Atlântica; Fundação Biodiversitas; Instituto de Pesquisas Ecológicas; Secretaria do Meio Ambiente do Estado de São Paulo \& Instituto Estadual de Florestas-MG. 2000. Avaliação e Ações Prioritárias para a Conservação da Biodiversidade da Mata Atlântica e Campos Sulinos. Ministé- rio do Meio Ambiente/SBF, Brasília.

Dittrich, V.A.O. 2005. Estudos Taxonômicos no Gênero Blechnum L. (Pteridophyta: Blechnaceae) para as Regiões Sudeste e Sul do Brasil. Tese de Doutorado. Universidade Estadual Paulista Júlio de Mesquita Filho.

Ebihara, A.; Dubuisson, J.Y.; Iwatsuki, K.; Hennequim, S. \& Ito, M. 2006. A taxonomic revision of Hymenophyllaceae. Blumea 51: 1-60.

Edwards, P.J. 1995. Selaginellaceae. In: B.L. Stannard (ed.), Flora of the Pico das Almas, Chapada Diamantina - Bahia, Brasil. Royal Botanic Gardens, Kew, p. 83-84.

Evans, A.M. 1969. Interspecific relationships in the Polypodium pectinatum-plumula complex. Annals of the Missouri Botanical Garden 55: 193-293.

Fernandes, I. 1997. Taxonomia e Fitogeografia de Cyatheaceae e Dicksoniaceae nas Regiões Sul e Sudeste do Brasil. Tese de Doutorado. Universidade de São Paulo.

Fernandes, I. 2003. Taxonomia dos representantes de Cyatheaceae do nordeste oriental do Brasil. Pesquisas Botânica 53: 7-53.

Ferreira, J.L. 2009. Schizaeales Reed (Pteridophyta) da Chapada Diamantina, Bahia, Brasil. Dissertação de Mestrado. Universidade Estadual de Feira de Santana. 44

Garcia, P.A. \& Salino, A. 2009. Dryopteridaceae (Polypodiopsida) no estado de Minas Gerais, Brasil. Lundiana 9: 3-27.

Giudice, G.E.; Luna, M.L.; Carrión, C. \& Sota, E.R. 2008. Revision of the genus Salpichlaena J. Sm. (Blechnaceae, Pteridophyta). American Fern Journal 98: 49-60.

Góes-Neto, A.; Marques, M.F.O.; Andrade, J.D. \& Santos, D.S. 2003. Lignicolous aphyllophoroid Basidiomycota in an Atlantic forest fragment in the semi-arid caatinga region of Brazil. Mycotaxon 88: 359-364. 
Hirai, R.Y. \& Prado, J. 2000. Selaginellaceae Willk. no estado de São Paulo, Brasil. Revista Brasileira de Botânica 23: 313339.

Hovenkamp, P.H. \& Miyamoto, F. 2005. A conspectus of the native and naturalized species of Nephrolepis (Nephrolepidaceae) in the world. Blumea 50: 279-322.

Kramer, K.U. \& Green, P.S. 1990. Pteridophytes and Gymnosperms. In: K. Kubitzki (ed.), The Families and Genera of Vascular Plants. Springer-Verlag, Berlin, p. 1-404.

Labiak, P.H. \& Matos, F.B. 2009. Cyathea atrocastanea, a new tree fern from the Atlantic Rain Forest of southeastern Brazil. Systematic Botany 34: 476-480.

Labiak, P.H. \& Prado, J. 1998. Pteridófitas epífitas da Reserva Volta Velha, Itapoá, Santa Catarina, Brasil. Boletim do Instituto de Botânica 11: 1-79.

Labiak, P.H. \& Prado, J. 2003. Grammitidaceae (Pteridophyta) no Brasil, com ênfase nos gêneros Ceradenia, Cochlidium e Grammitis. Hoehnea 30: 243-283.

Labiak, P.H. \& Prado, J. 2005a. As espécies de Lellingeria A.R.Sm. \& R.C.Moran (Grammitidaceae - Pteridophyta) do Brasil. Revista Brasileira de Botânica 28: 1-22.

Labiak, P.H. \& Prado, J. 2005b. As espécies de Melpomene e Micropolypodium (Grammitidaceae - Pteridophyta) no Brasil. Boletim de Botânica da Universidade de São Paulo 23: 51-69.

Labiak, P.H. \& Prado, J. 2008. New combinations in Serpocaulon and a provisional key for the Atlantic Rain Forest species. American Fern Journal 98: 139-159.

Lellinger, D.B. 2002. A Modern Multilingual Glossary for Taxonomic Pteridology. American Fern Society, Washington.

León, B. 1992. A Taxonomic Revision of the Fern Genus Campyloneurum (Poypodiaceae). Tese de Doutorado. Universidad Mayor de San Marcos.

Macedo, T.S.; Góes-Neto, A. \& Nonato, F.R. 2011. Primeira ocorrência de Thelypteris villosa (Link) C. F. Reed (Thelypteridaceae) para o Nordeste do Brasil. Acta Botanica Brasilica 25: 727-728. 45

Marques, M.F.O.; Moraes Júnior, V.O.; Santos, S.M.L.; Gusmão, L.F.P. \& Maia, L.C. 2007. Fungos conidiais lignícolas em um fragmento de Mata Atlântica, Serra da Jibóia, BA. Revista Brasileira de Biociências 5: 1186-1188.

Matos, F.B.; Amorim, A.M. \& Labiak, P.H. 2010. The ferns and lycophytes of a montane tropical forest in southern Bahia, Brazil. Journal of the Botanical Research Institute of Texas 4: $1-14$.

Mickel, J.T. \& Smith, A.R. 2004. The pteridophytes of Mexico. Memoirs of the New York Botanical Garden 88: 1-1055.

Moran, R.C. 1986. The neotropical fern genus Olfersia. American Fern Journal 76: 161-178.

Moran, R.C. 1987. Monograph of the neotropical fern genus Polybotrya (Dryopteridaceae). Illinois Natural History Survey Bulletin 34: 1-138.

Moran, R.C. 2000. Monograph of the neotropical species of Lomariopsis (Lomariopsidaceae). Brittonia 52: 55-111.

Navarrete, H. \& Øllgaard, B. 2000. The fern genus Dennstaedtia (Dennstaedtiaceae) in Ecuador - new characters, new species and new combinations. Nordic Journal of Botany 20: 319346.

Noblick, L.R. \& Brito, I.C. 1984. Pteridófitas dos arredores da Vila de Lamarão do Passé, São Sebastião do Passé, Bahia. Sitientibus 2: 17-28.
Nonato, F.R. 2004. A Família Hymenophyllaceae (Pteridophyta) na Região Nordeste do Brasil: estudo florístico e fitogeográfico. Tese de Doutorado. Universidade Federal do Rio Grande do Sul.

Nonato, F.R. 2005. Pteridófitas. In: F.A. Juncá, L. Funch \& W. Rocha (eds), Biodiversidade e Conservação da Chapada Diamantina. Ministério do Meio Ambiente, Brasília, p. 211223.

Nonato, F.R. \& Windisch, P.G. 2004. Vittariaceae (Pteridophyta) do Sudeste do Brasil. Revista Brasileira de Botânica 27: 149161.

Novelino, R.F. \& Oliveira, J.E.Z. (eds) 1999. Flora do Parque Estadual do Ibitipoca Minas Gerais, Brasil: Elaphoglossaceae (Pteridophyta). Instituto Brasileiro do Meio Ambiente e dos Recursos Naturais Renováveis, Brasília.

Øllgaard, B. 1995. Lycopodiaceae. In: B.L. Stannard (ed.), Flora of the Pico das Almas, Chapada Diamantina-Bahia, Brasil. Royal Botanic Gardens, Kew, p. 80-83.

Østergaard-Andersen, E. \& Øllgaard, B. 2001. Gleicheniaceae. In: G. Harling \& L. Andersson (eds), Flora of Ecuador. Vol. 66. Göteborg University, Göteborg, p. 105-170.

Pacheco, L. 1995. Hymenophyllaceae. (R.C. Moran \& R. Riba, Psilotaceae a Salviniaceae). In: G. Davidse, M. Sousa \& S. Knapp (eds). Flora Mesoamericana. Vol. 1. Universidad Nacional Autónoma de México, Ciudad de México, p. 62-83.

Paciência, M.L.B. \& Prado, J. 2004. Efeitos de borda sobre a comunidade de pteridófitas na Mata Atlântica na região de Una, sul da Bahia, Brasil. Revista Brasileira de Botânica 27: 641653.

Paciência, M.L.B. \& Prado, J. 2005. Distribuição da assembléia de pteridófitas em uma paisagem fragmentada de Mata Atlântica, no sul da Bahia, Brasil. Hoehnea 32: 103-117.

Pichi-Sermolli, R.E.G. 1996. Authors of Scientific Names in Pteridophyta. Royal Botanic Gardens, Kew.

Prado, J. 1995. Ferns. In: B.L. Stannard (ed.), Flora of the Pico das Almas, Chapada Diamantina-Bahia, Brasil. Royal Botanic Gardens, Kew, p. 85-110.

Prado, J. 2003. Pteridófitas. In: D.C. Zappi, E. Lucas, B.L. Stannard, E.N. Lughadha, J.R. Pirani, L.P. Queiroz, S. Atkins, D.J.N. Hind, A.M. Giulietti, R.M. Harley \& A.M. Carvalho (eds), Lista das plantas vasculares de Catolés, Chapada Diamantina, Bahia, Brasil. Boletim de Botânica da Universidade de São Paulo 21: 359-360.

Prado, J. \& Freitas C.A.A. 2005. Flora da Reserva Ducke, Amazonas, Brasil: Pteridophyta - Cyatheaceae. Rodriguésia 56: 35-37.

Prado, J. \& Moran, R.C. 2008. Revision of the neotropical species of Triplophyllum (Tectariaceae). Brittonia 60: 103-130.

Prado, J. \& Windisch, P.G. 2000. The genus Pteris L. (Pteridaceae) in Brazil. Boletim do Instituto de Botânica 13: 103-199.

Queiroz, L.P.; Sena, T.S.N \& Costa, M.J.S.L. 1996. Flora Vascular da Serra da Jibóia, Santa Terezinha - Bahia. I. O Campo Rupestre. Sitientibus 15: 27-40.

Ramos, C.G.V. \& Sylvestre, L.S. 2010. Lycopodiaceae no Parque Nacional do Itatiaia, RJ e MG, Brasil. Acta Botanica Brasilica 24: $25-46$.

Salino, A. \& Almeida, T.E. 2009. Pteridófitas. In: J.R. Stehmann, R.C. Forzza, A. Salino, M. Sobral, D.P. Costa \& L.H.Y. Kamino (eds), Plantas da Floresta Atlântica. Jardim Botânico do Rio de Janeiro, Rio de Janeiro, p. 19-26. 47

Salino, A. \& Semir, J. 2002. Thelypteridaceae (Polypodiophyta) 
do estado de São Paulo: Macrothelypteris e Thelypteris subgêneros Cyclosorus e Steiropteris. Lundiana 3: 9-27.

Salino, A. \& Semir, J. 2003. Notas sobre duas espécies de Thelypteris Schmidel (Thelypteridaceae -Pteridophyta) do Brasil. Acta Botanica Brasilica 17: 515-521.

Sandes, A.B. 2003. Releitura socioambiental da Serra da Jibóia: Um estudo voltado para a produção continuada em Educação Ambiental. Monografia (Especialização em Educação Ambiental para Sustentabilidade). Universidade Estadual de Feira de Santana.

Smith, A.R. 1986. Revision of the neotropical fern genus Cyclodium. American Fern Journal 76: 56-98.

Smith, A.R.; Pryer, K.M.; Schuettpelz, E.; Korall, P.; Schneider, H. \& Wolf, P.G. 2006. A classification for extant ferns. Taxon 55: 705-731. Smith, A.R.; Pryer, K.M.; Schuettpelz, E.; Korall, P.; Schneider, H. \& Wolf, P.G. 2008. Ferns classification. In: T.A. Ranker \& C.H. Haufler (eds), Biology and Evolution of Ferns and Lycophytes. Cambridge University Press, Cambridge. p. 417-462.

Stolze, R.G. 1983. Ferns and fern allies of Guatemala. Part III: Marsileaceae, Salviniaceae and the fern allies. Fieldiana Botany, New Series 2: 1-91.

Sylvestre, L.S. 2001. Revisão das Espécies da Família Aspleniaceae A.B. Frank Ocorrentes no Brasil. Tese de Doutorado. Universidade de São Paulo.

Thiers, B. 2010. [continuously updated]. Index Herbariorum: A global directory of public herbaria and associated staff. New York Botanical Garden's Virtual Herbarium. Disponível em: http://sweetgum.nybg.org/ih/; acesso em: 7 abr. 2010.

Tryon, R.M \& Stolze, R.G. 1989a. Pteridophyta of Peru. Part I: 1. Ophioglossaceae - 12. Cyatheaceae. Fieldiana Botany, New Series 20: 1-145.

Tryon, R.M \& Stolze, R.G. 1989b. Pteridophyta of Peru. Part II: 13. Pteridaceae - 15. Dennstaedtiaceae. Fieldiana Botany, New Series 22: 1-128.

Tryon, R.M \& Stolze, R.G. 1993. Pteridophyta of Peru. Part V: 18. Aspleniaceae - 21. Polypodiaceae. Fieldiana Botany, New Series 32: 1-190.

Valente, E.B. \& Porto, K.C. 2006. Hepáticas (Marchantiophyta) de um fragmento de Mata Atlântica na Serra da Jibóia, Município de Santa Teresinha, BA, Brasil. Acta Botanica Brasilica 20: 433-441.

Windisch, P.G. 1992. Pteridófitas da Região Norte-ocidental do Estado de São Paulo: guia para estudos e excursões. 2 ed. Universidade Estadual Paulista, São José do Rio Preto.

Winter, S.L.S.; Mynssen, C.M. \& Prado, J. 2007. Adiantum no arboreto do Jardim Botânico do Rio de Janeiro, Brasil. Rodriguésia 58(4): 847-858.

Zuquim, G.; Costa, F.R.C.; Prado, J. \& Tuomisto, H. 2008. Guia de Samambaias e Licófitas da REBIO Uatumã - Amazônia Central. 1. ed. Attema design editorial, Manaus.

\section{Lista de Exsicatas}

Andrade, I.M. 835 (15.12); Cardoso, D. 2413 (6.14); Harley, R. in PCD 5860 (4.2); Macedo, T.S 72 (7.2), 73 (9.3), 74 (1.4), 75 (15.15), 76 (20.1), 77 (4.1), 78 (6.16), 79 (9.1), 80 (6.12), 81 (15.4), 82 (15.7), 83 (3.2), 84 (20.2), 86 (15.3), 87 (6.1), 88 (5.2), 89 (2.1), 91 (10.4), 92 (22.3), 93 (15.8), 95 (17.11), 96 (8.1), 99 (17.10), 103 (20.2), 104, 105 (20.1), 106 (6.3), 107 (15.5), 108 (8.4), 109 (1.3), 110 (17.9), 111 (17.1), 112 (11.1), 113 (4.3), 114 (15.12), 115 (8.4), 116 (17.2), 117 (15.5), 118 (15.6), 120 (15.16), 121 (6.3), 122 (7.1), 123 (7.2), 125 (8.3), 126 (1.3), 127 (1.1), 129 (17.1), 130 (7.3), 131 (22.2), 132 (15.1), 133 (2.3), 134 (6.7), 135 (10,1), 136 (6.3), 137 (3.1), 138 (17.2), 139 (12.1), 140 (1.1), 141 (9.1), 142 (1.2), 143 (15.4), 144 (3.3), 145 (8.3), 146 (8.10), 148 (8.1), 149 (6.4), 150 (17.8), 151 (21.1), 152 (8.10), 153 (18.1), 154 (6.15), 155 (2.2), 156 (17.12), 157 (6.6), 158 (2.3), 159 (15.2), 160 (4.5), 161 (4.1), 162 (13.1), 163 (9.2), 164 (8.6), 165 (17.4), 167 (17.5), 168 (22.3), 169 (17.12), 170 (6.6), 171 (10.1), 172 (17.6), 173 (14.1), 174 (15.13), 175 (15.14), 176 (10.4), 177 (6.9), 178 (15.10), 179 (9.2), 180 (8.2), 181 (8.5), 182 (1.1), 183 (19.1),
184 (15.7), 185 (8.9), 187 (9.3), 188 (3.2), 189 (15.5), 190 (11.2), 191 (15.10), 192 (4.5), 193 (10.3), 194 (2.3), 195 (15.16), 196 (6.17), 197 (10.3), 198 (8.5), 199 (8.2), 200 (10.2), 201 (6.16), 202 (16.1), 204 (6.8), 205 (15.2), 206 (15.11), 207 (15.9), 209 (10.1), 210 (13.1), 211 (6.12), 212 (21.1), 213 (2.2), 214 (1.2), 216 (8.1), 217 (8.6), 219 (6.9), 220 (6.13), 221 (6.5), 222 (6.10), 223 (6.11), 224 (4.4), 225 (15.1); Melo, E 1250 (12.1), 1336 (4.2), 1688 (10.2), 1692 (7.2), 1960 (5.2), 2384 (8.8), 2660 (6.17), 2664 (8.7), 2666 (9.2); Noblick, L.R. 3208 (10.2), 3307 (17.10), 3318 (1.4), 3319 (11.3), 3338 (6.9), 3342 (8.2), 3343 (19.1), 3346 (9.1), 3351 (4.3), 3742 (6.4), 3745 (5.2), 4354 (4.2), 4357 (8.8), 4359 (19.1); Nonato, F.R. 790 (20.2), 802 (17.1), 804 (5.1), 805 (3.1), 807 (17.3), 810 (17.7), 821 (2.1), 824 (8.4), 829 (8.3), 1056 (17.2), 1057 (3.2), 1058 (1.3), 1060 (22.1), 1061 (17.9), 1062 (17.4), 1063 (3.1). 1076 (8.8); Queiroz, L.P. 1078 (15.15), 1565 (15.4), 2938 (11.3), 3006 (4.2), 3177 (15.3), 3828 (1.4); Senna, L.R. 22 (16.1). 50 